\title{
Expansion of gamma-butyrolactone signaling molecule biosynthesis to phosphotriester natural products
}

Yuta Kudo ${ }^{\mathrm{a}, \mathrm{b}, \mathrm{c}}$, Takayoshi Awakawaa,d, Yi-Ling Due, Peter A. Jordan ${ }^{\mathrm{a}}$, Kaitlin E. Creamer, Paul R. Jensen ${ }^{a}$, Roger G. Linington ${ }^{\dagger}$, Katherine S. Ryan ${ }^{e}$, Bradley S. Moore ${ }^{\star, a, g}$

${ }^{a}$ Center for Marine Biotechnology and Biomedicine, Scripps Institution of Oceanography, University of California San Diego, La Jolla, California 92093, United States

b Frontier Research Institute for Interdisciplinary Sciences, Tohoku University, 6-3 Aramaki-Aza-Aoba, Aoba-ku, Sendai, Miyagi 980-8578, Japan

c Graduate School of Agricultural Science, Tohoku University 468-1 Aramaki-Aza-Aoba, Aoba-ku, Sendai, Miyagi 980-8572, Japan

d Graduate School of Pharmaceutical Sciences, The University of Tokyo, 7-3-1 Hongo, Bunkyo-ku, Tokyo 113-0033, Japan

e Department of Chemistry, University of British Columbia, Vancouver, British Columbia V6T 1Z1, Canada

${ }^{\mathrm{f}}$ Department of Chemistry, Simon Fraser University, Burnaby, British Columbia V5A 1S6, Canada

g Skaggs School of Pharmacy and Pharmaceutical Sciences, University of California San Diego, La Jolla, California 92093, United States 


\begin{abstract}
Bacterial hormones, such as the iconic gamma-butyrolactone A-factor, are essential signaling molecules that regulate diverse physiological processes, including specialized metabolism. These low molecular weight compounds are common in Streptomyces species and display species-specific structural differences. Recently, unusual gammabutyrolactone natural products called salinipostins were isolated from the marine actinomycete genus Salinispora based on their anti-malarial properties. As the salinipostins possess a rare phosphotriester motif of unknown biosynthetic origin, we set out to explore its construction by the widely conserved 9-gene spt operon in Salinispora species. We show through a series of in vivo and in vitro studies that the spt gene cluster dually encodes the saliniphostins and newly identified A-factor-like gammabutyrolactones (Sal-GBLs). Remarkably, homologous biosynthetic gene clusters are widely distributed amongst many actinomycete genera, including Streptomyces, suggesting the significance of this operon in bacteria.
\end{abstract}




\section{Introduction}

Actinobacteria are a rich source of specialized metabolites that have been developed into life-saving drugs. Recent advances in genome sequencing and mining have revealed that Actinobacteria have far greater potential for secondary metabolite production than previously realized. ${ }^{1}$ Yet, much of this potential remains cryptic, as many biosynthetic genes are poorly expressed in normal laboratory incubation conditions. ${ }^{2}$ The manipulation of the signaling mechanisms for gene expression can be a key to activate the expression of dormant biosynthetic genes. ${ }^{3-5}$ However, the regulation of biosynthetic pathways, and the autoregulators themselves, remains poorly understood.

Among the known signaling molecules, gamma-butyrolactones (GBLs) are recognized to be involved in the regulation of morphological development and secondary metabolism in actinomycete bacteria, especially in the genus of Streptomyces. ${ }^{6-10}$ In contrast, among the metabolically prolific marine actinomycete genus Salinispora, far less is known about the signaling pathways regulating the biosynthesis of their rich repertoire of natural products. ${ }^{11-15}$ However the recently reported potent and selective anti-malarial compounds, salinipostins (Figure 1A, salinipostin A (1)) from Salinispora sp. RL08-036SPS-B, ${ }^{16,17}$ may shed some light on this. Salinipostins possesses a GBL ring analogous to A-factor, as well as a highly unusual phosphotriester ring. Two compounds, cyclipostins and cyclophostin (Figure 1C), from Streptomyces have this same structural motif and have been reported as hormone sensitive lipase and acetylcholinesterase inhibitors, respectively. ${ }^{18,19}$ These compounds are estimated to be derived from a similar pathway as the GBL biosynthetic pathway based on their structural similarity.

The most studied GBL compound is A-factor (Figure 1B) from Streptomyces griseus. ${ }^{20,21}$ The GBL structure is formed from the condensation of beta-ketoacyl acyl carrier protein (ACP) and dihydroxyacetone phosphate (Figure 1B) by the A-factor synthase AfsA followed by successive reduction by BprA and dephosphorylation. ${ }^{22}$ AfsA homologues are common in streptomycetes where they have been shown to be involved not just in GBL biosynthesis but also in the production of gamma-butenolides and furans. ${ }^{6,23-26}$

Recently, we showed that the AfsA homologue Spt9 in Salinispora bacteria is responsible for the construction of the salinipostins and its volatile byproducts, salinilactones. ${ }^{2,27,28}$ The spt9 gene is the terminal gene of a nine-gene biosynthetic locus 
(Figure $1 \mathrm{~A}$ ) that is broadly conserved in Salinispora species ${ }^{29}$ (spt was annotated as butyrolactone 1 in this reference). Herein, we report the functional characterization of $s p t$ genes, spt6 and spt9, toward salinipostin biosynthesis and show that the spt gene cluster is also responsible for the synthesis of novel, natural GBLs as co-products of salinipostin biosynthesis.

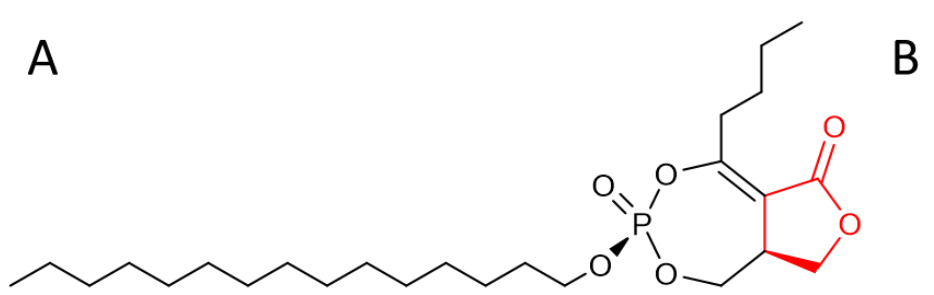

Salinipostin A (1) Salinispora sp.

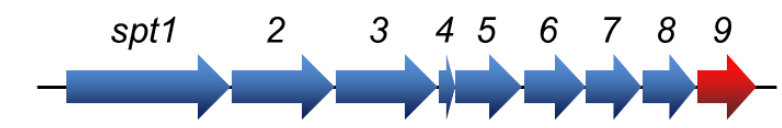

$\begin{array}{ll}\text { Spt1 } & \text { Phosphoenolpyruvate synthase } \\ \text { Spt2 } & \text { AMP-ligase } \\ \text { Spt3 } & \text { Nucleotidyltransferase } \\ \text { Spt4 } & \text { Acyl carrier protein } \\ \text { Spt5 } & \text { Thiolreductase } \\ \text { Spt6 } & \text { Nucleoside diphosphate kinase } \\ \text { Spt7 } & \text { UbiA type transferase } \\ \text { Spt8 } & \text { Flavin-dependent luciferase } \\ \text { Spt9 } & \text { Y-butyrolactone synthase (AfsA) }\end{array}$

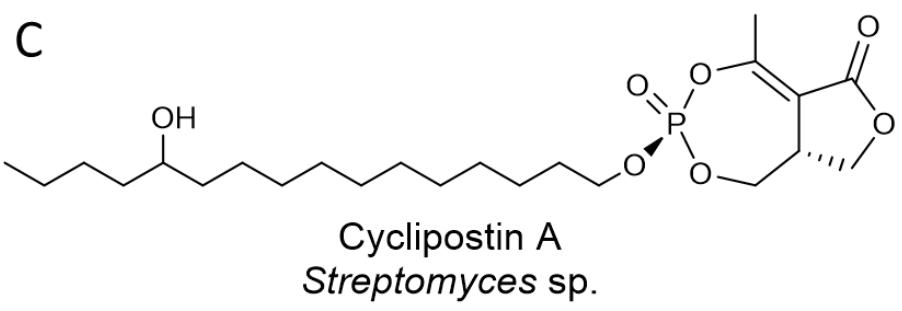<smiles>CC(C)CCCCC(=O)C1C(=O)OC[C@@H]1CO</smiles>

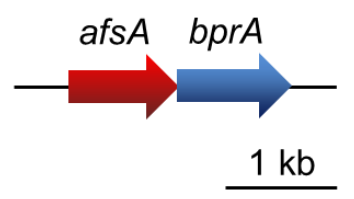

AfsA A-factor synthase BprA $\begin{aligned} & \text { Butenolide phosphate } \\ & \text { reductase }\end{aligned}$
A

Figure 1. Chemical structures of natural phosphotriester compounds and A-factor with their sources and biosynthetic gene clusters. (A) Salinipostin $A$ and its biosynthesis gene cluster from Salinispora tropica CNB-4402; (B) A-factor and its biosynthesis gene cluster,22; (C) cyclipostin $A$ and cyclophostin, whose biosynthetic genes have not yet been identified/predicted ${ }^{18,19}$. Gamma-butyrolactone structure and key relevant biosynthetic gene were highlighted in red in panel $(A)$ and $(B)$. 


\section{Results and discussion}

\section{Discovery of gamma-butyrolactone compounds from Salinispora species}

We previously reported the global transcriptional activity of biosynthesis gene clusters in Salinispora species and showed that the spt locus was involved with salinipostin biosynthesis through genetic inactivation of spt9 and concomitant loss of salinipostin. ${ }^{2}$ Upon re-examination of the $S$. tropica CNB-440 spt9-deletion mutant in comparison with the native CNB-440 strain by Liquid Chromatography-Mass Spectrometry (LC-MS), we identified compounds in addition to the salinipostins that were also abolished in the mutant (Figure 2B). Inspection of the molecular formulae of compounds $2\left(\mathrm{C}_{11} \mathrm{H}_{19} \mathrm{O}_{4}, \mathrm{~m} / \mathbf{z}\right.$ 215.1280, $[\mathrm{M}+\mathrm{H}]^{+}$calcd. 215.1278) and $3\left(\mathrm{C}_{10} \mathrm{H}_{17} \mathrm{O}_{4}, \mathrm{~m} / \mathrm{z}\right.$ 201.1126, $[\mathrm{M}+\mathrm{H}]^{+}$calcd. 201.1121) suggested that they could be simple, A-factor-like GBL compounds (Figure S1).

Generally, the production levels of GBLs in native strains are quite modest, reflecting the low effective concentration of the signaling molecules (e.g., A-factor, $10^{-9} \mathrm{M}$ ) ${ }^{30}$. As such, significant effort is often required to isolate and characterize GBLs as in the case of SCB1 and IM-2 in which several hundred liters of cultures were analyzed. ${ }^{31,32}$ To enhance the poor productivity of the $S$. tropica GBL compounds, we grew strain CNB-440 with Amberlite XAD-7HP resin to achieve an approximately 50-fold enhancement of GBL production (Figure S2). With this method, we purified $1.2 \mathrm{mg}$ of the most abundant GBL (Sal-GBL1, 2) from $3 \mathrm{~L}$ culture for comprehensive NMR analysis (Figures S20-23). Based on the 2D NMR analysis, the structure of 2 was confirmed as a new natural GBL containing an iso-hexanoyl sidechain (Figure 2A). The circular dichroism spectrum of 2 exhibited similar Cotton effects as the natural form of synthetic 3- $(R)$-A-factor ${ }^{33,34}$ (Figure S24), therefore establishing the stereochemistry at C-3 in 2 as $(R)$. This stereochemical configuration is consistent with the stereochemistry at C-3 in salinipostin ${ }^{16}$. A second analogue (Sal-GBL2, 3) was elucidated with a pentanoyl sidechain (Figure 2A, 3) based on the LC-MS comparison with a chemically synthesized standard (Figure S3, 25, 26).

We observed that compounds $\mathbf{2}$ and $\mathbf{3}$ are also produced in the other species of Salinispora producing salinipostins, namely S. arenicola CNS-205, S. mooreana CNT150 and Salinispora sp. RL08-036-SPS-B (Figure 2B, Figure S3), representing the first identification of A-factor-like GBL compounds in the genus of Salinispora. The production 
of 2, 3, and salinipostins were also completely abolished in S. arenicola CNS-205 $\Delta$ spt9 and Salinispora sp. RL08-036-SPS-B $\Delta s p t 9$, reinforcing that spt9 is essential for their biosynthesis (Figure 2B, Figure S3).

On the basis of the distinct chemical features of the salinipostins and Sal-GBLs and the gene composition of the spt gene cluster, we suspected that the biosynthetic pathway likely diverges at an early common intermediate. As such, we knocked out the putative nucleotide diphosphate-kinase spt6 gene in Salinispora sp. RL08-036-SPS-B and showed that this mutant produced 2, which lack a phosphotriester, but not salinipostins, with the phosphotriester group (Figure 2B). These results are consistent with our proposed, diverging pathway (Figure 3), whereby subsequent pyrophosphate formation via Spt6 redirects the biosynthetic pathway to salinipostins. 
A

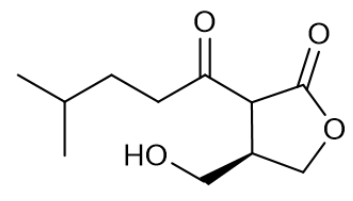

Sal-GBL1 (2)

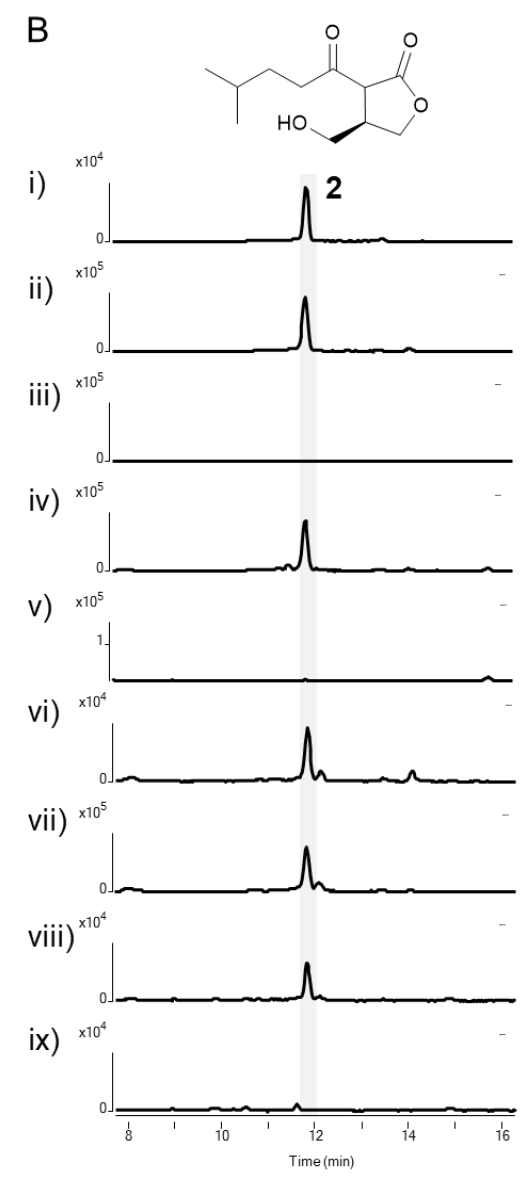<smiles>CCCCC(=O)C1C(=O)CCC1CO</smiles>

Sal-GBL2 (3)

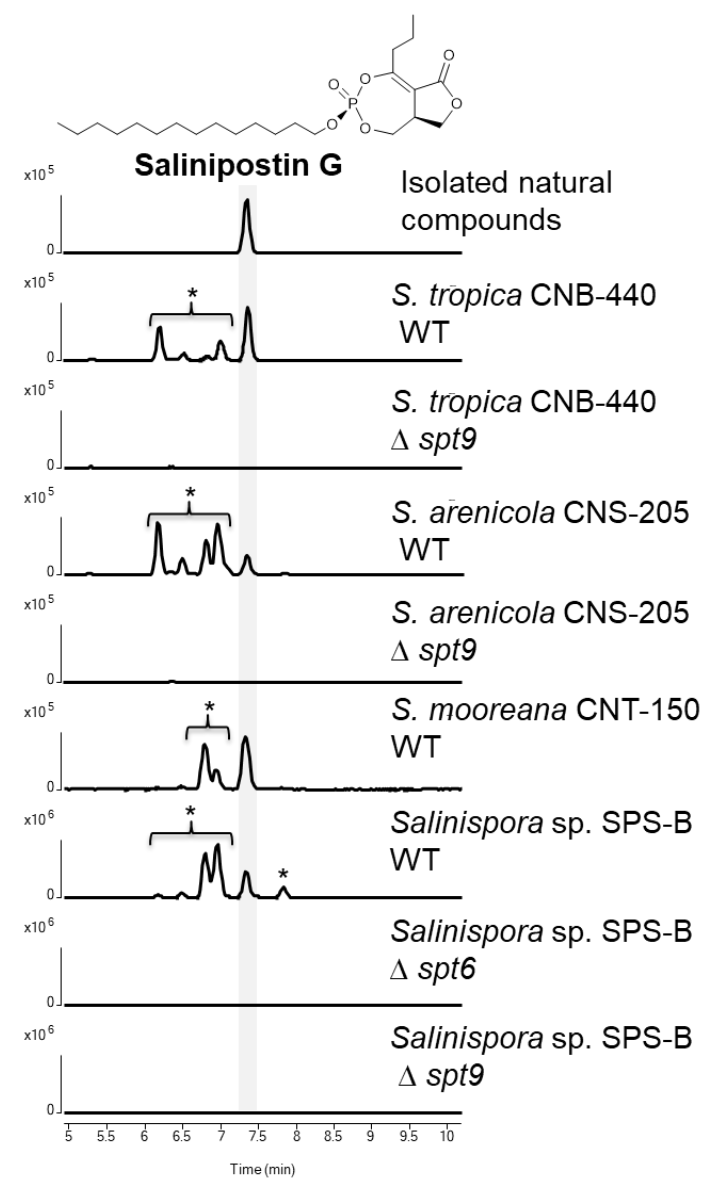

Figure 2. Structures and mutagenesis of spt products. (A) Structures of new natural GBLs isolated from S. tropica CNB-440, Sal-GBL1 (2) and Sal-GBL2 (3); (B) EIC at $\mathrm{m} / \mathrm{z}$ 215.1278 (Sal-GBL1, left column) and $\mathrm{m} / \mathrm{z} 445.2714$ (salinipostin $\mathrm{G}$, right column) for i) isolated natural compounds, ii) $S$. tropica CNB-440 wild type, iii) $S$. tropica CNB-440 $\Delta s p t 9$, iv) $S$. arenicola CNS-205 wild type, v) $S$. arenicola CNS-205 $\Delta s p t 9$, vi) $S$. mooreana CNT-150, vii) Salinispora sp. RL08-036-SPS-B wild type, viii) Salinispora sp. RL08-036-SPS-B $\Delta$ spt6, and ix) Salinispora sp. RL08-036-SPS-B $\Delta$ spt9. *Estimated as salinipostin analogues based on the high-resolution MS and/or MS/MS fragmentation pattern (Figures S4-8). 


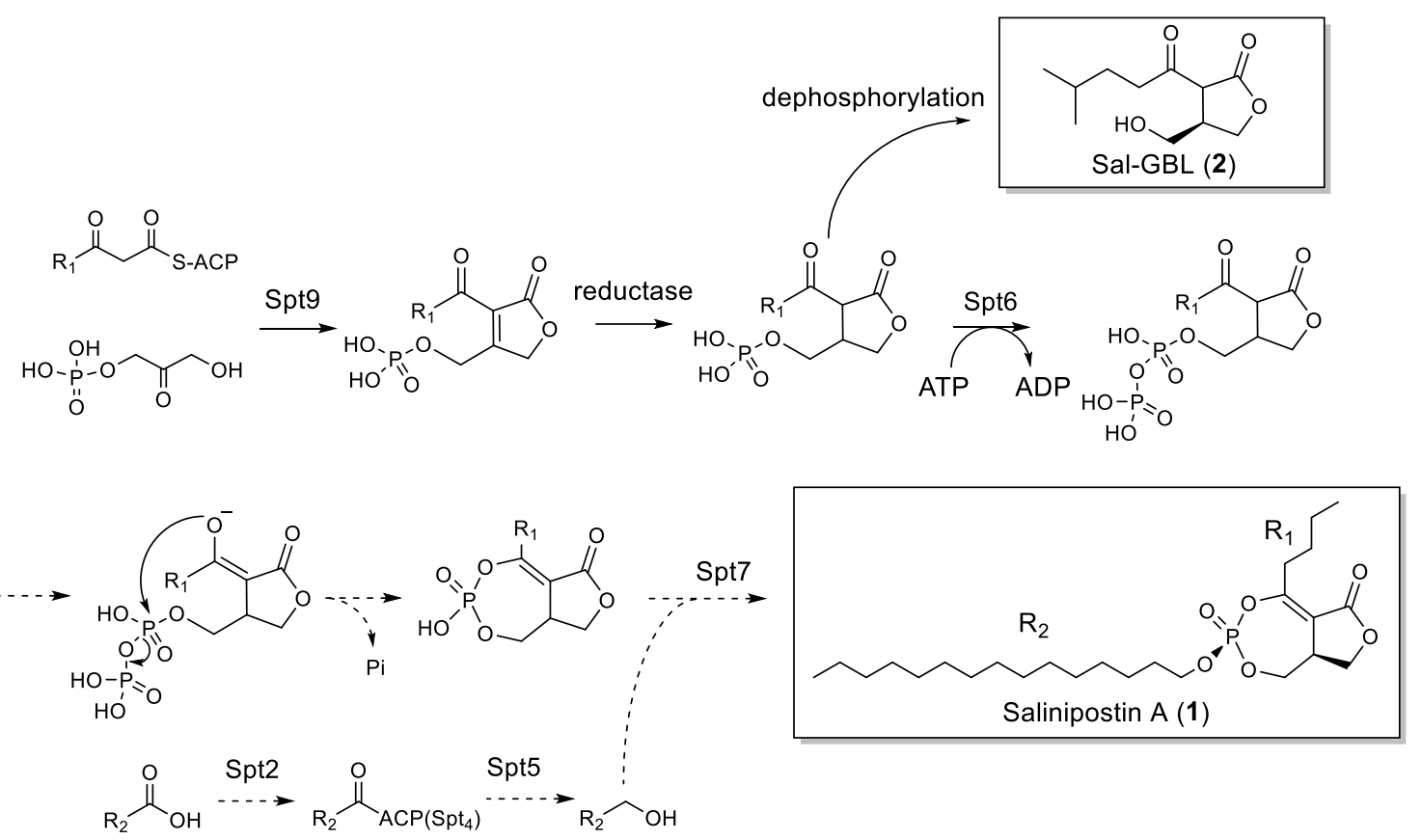

Figure 3. Enzymatic pathway toward Sal-GBL (2) and Sal-GBL pyrophosphate and hypothetical biosynthetic pathway to salinipostin A (1). Solid arrows represent confirmed biochemical reactions, while dashed arrows are proposed. See Figure $1 \mathrm{~A}$ for the putative functions of the Spt proteins.

\section{In vitro reconstitution of the gamma-butyrolactone structure}

To further evaluate salinipostin biosynthesis and its branchpoint with GBL synthesis, we next evaluated the in vitro activity of recombinant Spt9 based on prior examination of the homologous A-factor synthase Afs $\mathrm{A}^{22}$. We prepared the $\mathrm{N}$-terminus maltose-binding protein (MBP) and histidine tagged Spt9 (Spt9-H-MBP) from E. coli harboring pET28aMBP-spt9 and removed both affinity tags using TEV protease (Figure S18). We next synthesized both substrates: the beta-keto heptanoyl $N$-acetylcysteamine thioester (SNAC) (compound 4) as a substrate mimic of the ACP-bound substrate and dihydroxyacetone (5). ${ }^{35}$ We first observed the consumption of 4 in the enzymatic reaction mixture, however, a product peak was not detected in the LC-MS analysis. Therefore, we analyzed the reaction mixture using LC-MS immediately after short incubation periods. Incubation of tag-free Spt9 with substrates 4 and 5 (1 mM, each) in a phosphatecitrate buffer at $30^{\circ} \mathrm{C}$ for 10 min yielded a plausible phosphorylated butenolide compound (7) having the anticipated molecular formula $\mathrm{C}_{10} \mathrm{H}_{17} \mathrm{O}_{7} \mathrm{P}(\mathrm{m} / \mathrm{z} 277.0481 \text {, [M-H] }]^{-}$calcd. 
277.0483) and phosphate fragment ion at $m / z 96.9709$ ([M-H] calcd. for $\mathrm{H}_{2} \mathrm{O}_{4} \mathrm{P}, 96.9696$ ) (Figure 4B, Figure S15).

In A-factor biosynthesis, butenolide formation is followed by reduction with BprA, which is encoded immediately downstream of afs $A^{22}$. The spt gene cluster, however, does not encode a bprA homologue nor elsewhere nearby. Thus, we chose to incubate enzymatically produced 7 with the lysate prepared from the S. tropica CNB-440 $\Delta s p t 9$ deletion mutant along with NADPH (Figure 4B). In this way we produced compound 8 ( $\mathrm{m} / \mathrm{z}$ 279.0632, ([M-H] $]^{-}$calcd. 279.0639), which we validated by LC-MS analysis with synthetically prepared GBL-phosphate (8). Chemical reduction of the $\mathrm{C}-\mathrm{C}$ double bond in 7 with $\mathrm{NaBH}_{3} \mathrm{CN}$ also gave a relatively stable compound that eluted at the same retention time as the synthetic GBL-phosphate (8). These results are consistent with previous reports where the expression of recombinant AfsA in E. coli resulted in the production of A-factor like compounds in the host and reduction of butenolide was suggested to be catalyzed by the endogenous reductase in the bacteria. ${ }^{8,22}$ Thus, despite their low sequence homology at 35.8\% (pairwise positive, ClustalW alignment), our data unequivocally confirms that Spt9, like AfsA, catalyzes butenolide formation.

Although we assumed that passive cellular uptake of GBL-phosphate is unlikely based upon its polarity and negative charge, supplementation of $S$. tropica CNB-440 $\Delta$ spt9 with synthetic 8 recovered the production of salinipostin $B$, which contains $n$-butyl side chain (Figure 4C, S13). Conversely, the supplementation of GBLs 2 and $\mathbf{3}$ did not recover salinipostin production. Only in the case of supplementation with $\mathbf{8}$ were other possible salinipostin analogues containing the $\mathrm{C}_{4} \mathrm{H}_{8}$-sidechain also detected (Figures $\mathrm{S} 11, \mathrm{~S} 12$, S14), while natural salinipostins containing different sidechains were not generated (Figure 4C, (ii),(v)). These results support our hypothesis that salinipostin biosynthesis is initiated with the construction of the GBL. Furthermore, compound $\mathbf{3}$ was detected in the extract of $S$. tropica CNB-440 $\Delta$ spt9 supplemented with synthetic 8. Consistent with that observation, lysate of $S$. tropica CNB-440 $\Delta s p t 9$ similarly showed weak dephosphorylation activity. The incubation of $\mathbf{8}$ with commercial alkaline phosphatase (CIP) reliably gave 3 (Figure S16). Because there are no dedicated phosphatases in the spt gene cluster, we assume that this dephosphorylation was catalyzed by a nonspecific bacterial phosphatase, as similarly implied in A-factor biosynthesis. 
Our investigations of salinipostin biosynthesis indicated the GBL-phosphate 8 is a biosynthetic intermediate of salinipostin. As a prelude to phosphodiester ring formation, we hypothesized that activation of the phosphate group of $\mathbf{8}$ is an absolute requirement. Biochemically this is achieved through pyrophosphate formation as seen in the formation of the phosphodiester ring in cyclic-AMP, where adenylate cyclase converts ATP into cyclic AMP along with releasing a pyrophosphate as a leaving group ${ }^{36}$. Our mutant analysis confirmed that the spt6 gene encoding a diphosphate kinase is essential for the production of salinipostin as described above. Therefore, we further investigated the in vitro function of Spt6. We tested the enzymatic phosphorylation using the His-tagged Spt6 (H-Spt6) purified from E. coli harboring pET28a-spt6 (Figure S19). Incubation of $\mathrm{H}$ Spt6 and 8 with ATP and $\mathrm{Mg}^{2+}$ in HEPES buffer $(\mathrm{pH} 8)$ yielded the GBL-pyrophosphate (9), showing a fragment ion at $m / z 176.9358\left([\mathrm{M}-\mathrm{H}]^{-}\right.$calcd. for $\left.\mathrm{H}_{3} \mathrm{O}_{7} \mathrm{P}_{2}, 176.9359\right)$ derived from the pyrophosphate group in the both hydrophilic interaction chromatography (HILIC) LC-MS/MS (Figure 4D, E) and reversed-phase (RP) LC-MS/MS analyses (Figure S17). Thus, we hypothesize that 9 is the first dedicated biosynthetic intermediate in the salinipostin pathway and is required for the formation of the cyclic phosphodiester group. Few enzymes catalyze phosphorylation reactions on phosphorylated substrates in secondary metabolism. One example is $\mathrm{CalQ}$, which forms a diphosphate secondary metabolite, the protoxin phosphocalyculin A from toxic calyculin $\mathrm{A}^{37}$, but Spt6 shares low sequence identity with $\mathrm{CalQ}(13.9 \%$, ClustalW alignment).

We anticipate that the remainder of the pathway from the GBL pyrophosphate 9 to the salinipostins and its highly unusual phosphotriester core involves additional enzymes encoded within the spt locus as proposed in Figure 3. Biochemical experiments are presently underway. 
A

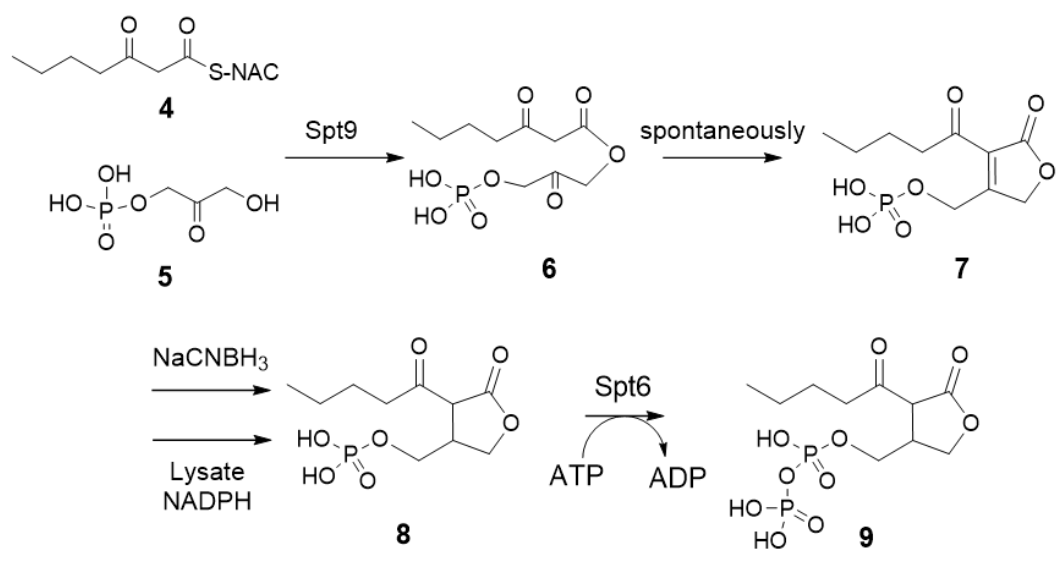

B

C
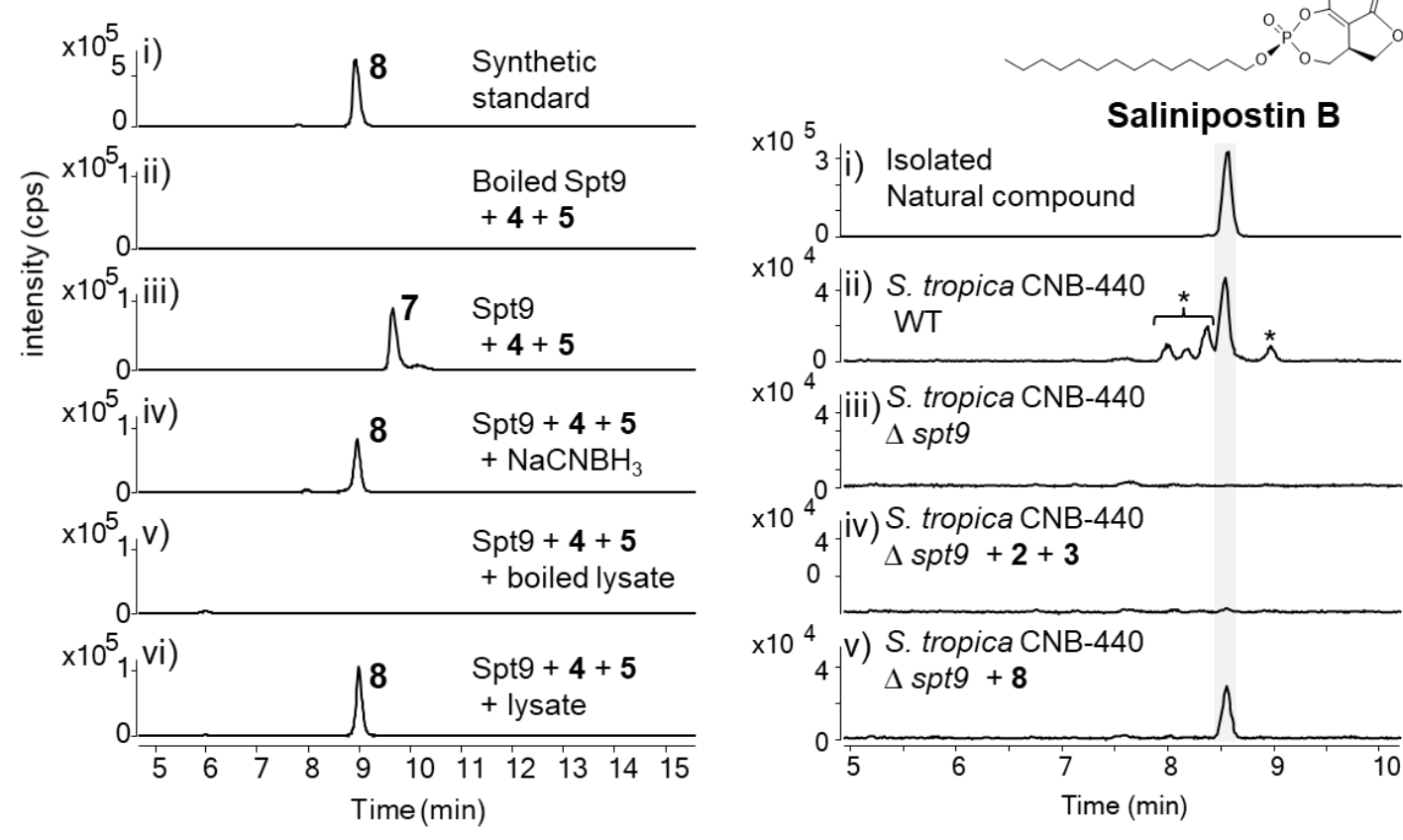
$\times 10^{4}$ - iii) S. tropica CNB-440

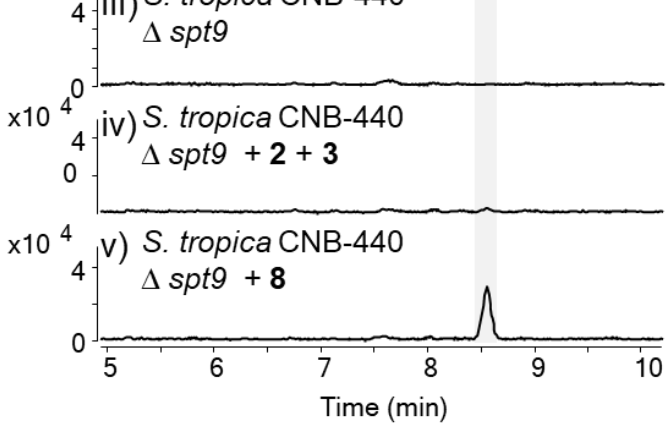

D
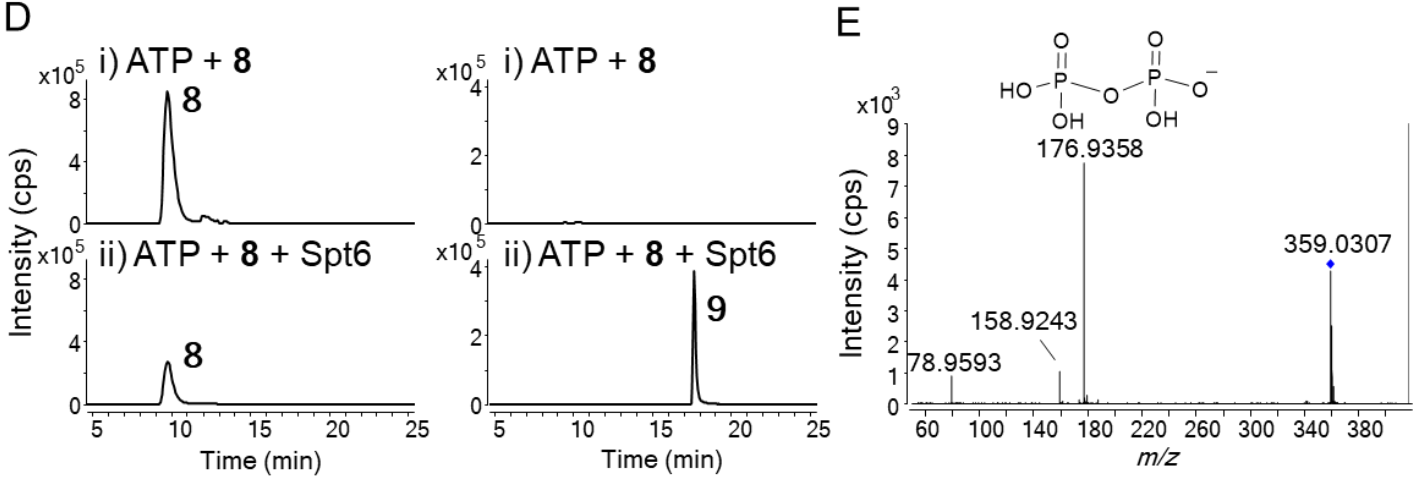

Figure 4. Gamma-butyrolactone structure formation in the biosynthesis of salinispostin. (A) In vitro reaction scheme, (B) Extracted ion chromatograms (EICs) for in vitro reaction mixtures: (i) Synthetic standard 8, (ii) $\mathbf{4}$ and $\mathbf{5}$ treated with boiled Spt9, (iii) $\mathbf{4}$ and $\mathbf{5}$ treated with Spt9, (iv) $\mathbf{4}$ and $\mathbf{5}$ treated with Spt9, then with $\mathrm{NaCNBH}_{3}$, (v) $\mathbf{4}$ and $\mathbf{5}$ treated with 
Spt9, then with boiled lysate, and (vi) $\mathbf{4}$ and $\mathbf{5}$ treated with Spt9, then with lysate. EIC at $\mathrm{m} / \mathrm{z} 279.0639$ for (i), (iv), (v) and (vi), and $\mathrm{m} / \mathrm{z} 277.0483$ for (ii) and (iii). (C) EICs at $\mathrm{m} / \mathrm{z}$ 459.2870 for XAD extracts from the feeding experiment: (i) isolated salinipostin $B$, (ii) $S$. tropica CNB-440 wild-type, (iii) S. tropica CNB-440 $\Delta$ spt9, (iv) S. tropica CNB-440 $\Delta s p t 9$ supplemented with 2 and 3, and (v) S. tropica CNB-440 $\Delta$ spt9 supplemented with 8. *Estimated as the salinipostin analogues based on the high-resolution MS and MS/MS fragmentation pattern (Figures S9,10). (D) HILIC-LC-MS EICs for in vitro reaction of phosphorylation of Sal-GBL2 phosphate (8), (i) 8, ATP and $\mathrm{Mg}^{2+}$ without H-Spt6 (ii) 8 , ATP and $\mathrm{Mg}^{2+}$ with H-Spt6. EICs at $\mathrm{m} / z 279.0639$ (8, left column) and $\mathrm{m} / \mathrm{z} 359.0302$ (9, right column): (E) MS/MS spectrum of 9 with the structure of fragment ion, $m / z 177$.

\section{Distribution and gene content of salinipostin-like biosynthetic gene clusters.}

The salinipostin biosynthetic gene cluster (spt1-9) is conserved at the genus level in Salinispora ${ }^{29}$. Using a targeted genome-mining approach, we identified nine genera in addition to Salinispora that maintain spt-like biosynthetic gene clusters (Figure 5). The spt-like gene clusters were identified in six diverse Actinobacterial families: Nocardiaceae, Tsukamurellaceae, Mycobacteriaceae, Pseudonocardiaceae, Dietziaceae, and Streptomycetaceae. Notably, spt-like gene clusters were found outside of the Streptomycetaceae where the gamma-butyrolactone A-factor and spt9 homolog afs $A$ were characterized. Spt1, spt3, spt5, spt6, spt7, and spt9 are conserved across all spt-like gene clusters (Figure 5), although spt2-3 and spt6-9 gene fusions were observed in some strains. Spt8 was uniquely observed in the Salinispora spt gene cluster. The organization of the spt biosynthetic gene cluster is largely conserved across multiple families of bacteria, ultimately suggesting that these diverse taxa have the capability to produce salinipostin-like phophotriester GBLs. A detailed analysis of spt gene distribution, organization, and evolutionary history will be the subject of another study (Creamer et al. 2020 bioRxiv). 


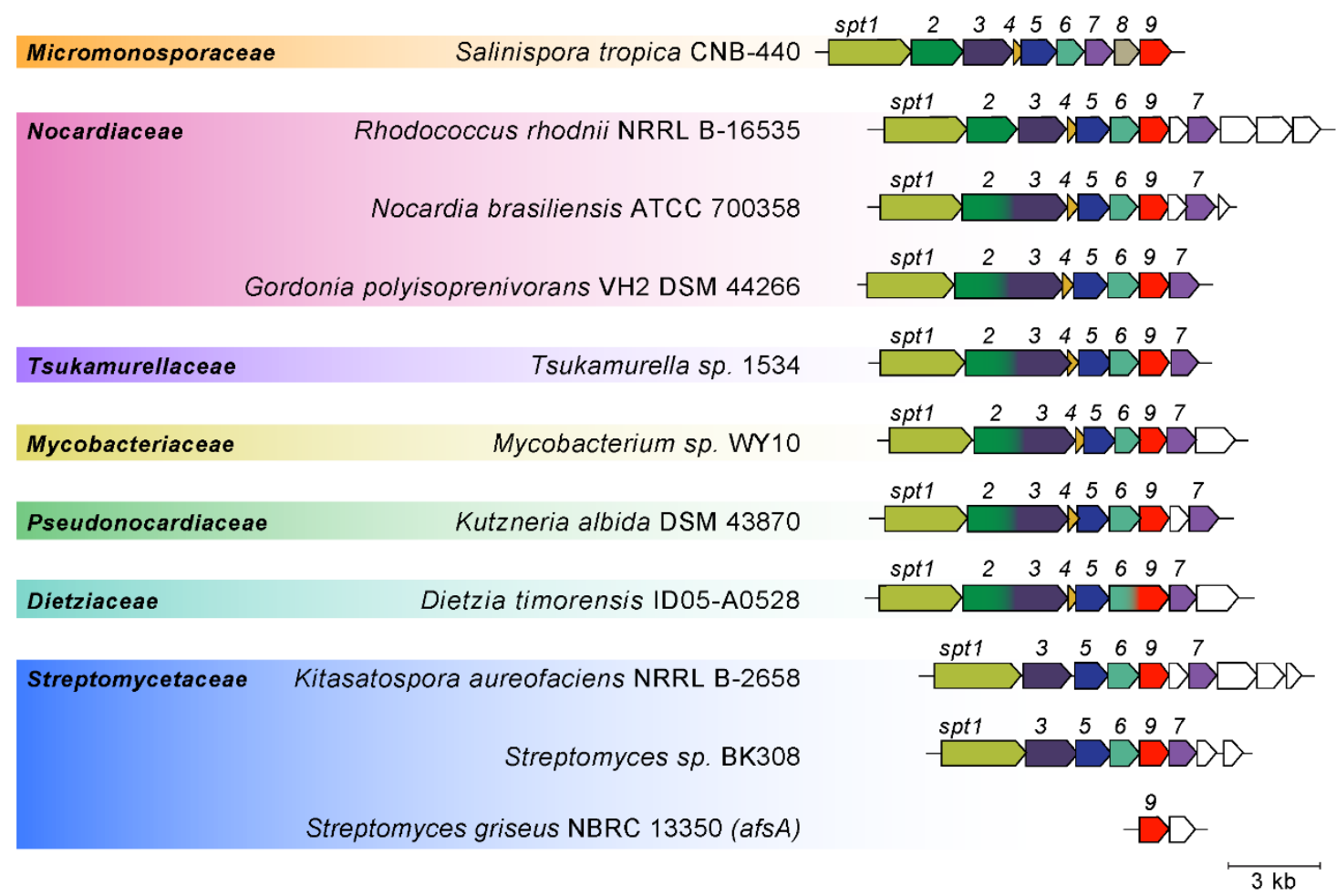

Figure 5. Spt-like biosynthetic gene clusters observed in diverse actinomycetes. Genes are colored by conserved Pfam function relative to spt1-9 in S. tropica; white indicates no relation to spt1-9. Spt2-3 and Spt6-9 represent gene fusions. Products are known from S. tropica (salinipostins and Sal-GBLs) and S. griseus (A-factor).

In conclusion, we established the early steps of salinipostin biosynthesis in Salinispora bacteria and showed that the phosphorylated GBL $\mathbf{8}$ is the branchpoint metabolic intermediate to the salinipostins and the newly identified Sal-GBL1 (2) and Sal-GBL2 (3) A-factor-like compounds. Intriguingly, the spt locus may thus have a dual biological purpose in the construction of both butyrolactone chemotypes whose native Salinispora functions have yet to be determined. While no small molecules from Salinispora have yet been experimentally established as autoregulators, Salinispora also produce acylhomoserine lactones that are known to mediate quorum sensing in gram-negative bacteria. ${ }^{38}$ Future investigations on the function of these molecules will undoubtedly shed light on the regulatory mechanism of secondary metabolism in Salinispora.

Our work also opens the door to establishing the biochemical logic for the construction of salinipostin's highly unusual phosphotriester functionality that is shared by the 
streptomycete molecules cyclipostin and cyclophostin. The high energy GBL pyrophosphate 9 is chemically predisposed for an intramolecular cyclization reaction with loss of phosphate to a cyclic phosphodiester GBL intermediate as shown in Figure 3. Condensation with a fatty alcohol constructed with Spt2/4/5 theoretically completes the pathway to the salinipostins. This proposed pathway anticipates the biosynthesis of cyclipostin and cyclophostin, which together with the salinipostins, may be more common in actinomycete biology than previously thought given the wide distribution of spt-like biosynthesis gene clusters (Figure 5). As such, we hypothesize that salinipostin-like phosphotriester GBLs may function as a new class of signaling molecules. Interrogation of salinipostin biosynthetic gene clusters may represent a key step in further unlocking the biosynthetic potential in Salinispora and other actinomycetes.

\section{DMETHODS}

\section{General}

The high-resolution MS spectra were recorded on an Agilent 6530 Accurate-Mass qTOF spectrometer, equipped with a dual ESI ionization source and an Agilent 1260 LC system. Acquisition parameters of the mass spectrometer were following, range $80-850 \mathrm{~m} / \mathrm{z}$, MS scan rate $2 / \mathrm{sec}, \mathrm{MS} / \mathrm{MS}$ scan rate $3 / \mathrm{sec}$, fixed collision energy $20 \mathrm{eV}$, source gas temperature $300^{\circ} \mathrm{C}$, gas flow $11 \mathrm{~L} / \mathrm{min}$, nebulizer $45 \mathrm{psig}$, scan source parameters: VCap 3000, fragmentor $175 \mathrm{~V}$, skimmer $65 \mathrm{~V}$, Octopole RF Peak $750 \mathrm{~V}$. LC-MS grade acetonitrile (MeCN), water and formic acid were purchased from Thermo Fisher Scientific (Waltham, Massachusetts, USA). Figures for mass spectral data were created in Mass Hunter (Agilent Technologies). Low-resolution LC-MS measurements were carried out on a Bruker Amazon SL ESI-Ion Trap mass spectrometer with Agilent Technologies 1200 Series HPLC system. LC-MS data was processed using Bruker Compass Data Analysis. The NMR spectra were recorded on a BRUKER Avance (600 MHz, CryoProbe) spectrometer in the solvents indicated. Signals are reported in ppm with the internal chloroform signal at $7.26 \mathrm{ppm}\left({ }^{1} \mathrm{H}\right)$ and $77.16 \mathrm{ppm}\left({ }^{13} \mathrm{C}\right)$, or the internal $\mathrm{CD}_{3} \mathrm{OD}$ signal at $3.31 \mathrm{ppm}\left({ }^{1} \mathrm{H}\right)$ and $49.0 \mathrm{ppm}\left({ }^{13} \mathrm{C}\right)$ as standard. Circular dichroism (CD) measurement of Sal-GBL1 (2) was obtained on an Aviv CD spectrometer model 62DS using a $1 \mathrm{~nm}$ 
bandwidth in a $0.5 \mathrm{~cm}$ cell at a concentration of $7.0 \mathrm{mM}$ at $25^{\circ} \mathrm{C}, 3 \mathrm{sec} / \mathrm{scan}, 200 \mathrm{~nm}$ to $500 \mathrm{~nm}$.

\section{Bacterial strains}

Salinispora tropica CNB-440 (accession: NC_009380.1), S. arenicola CNS-205 (accession: NC_009953.1), S. mooreana CNT-150 (accession: NZ_AQZW00000000 or KB900614.1), S. oceanensis CNT-854 (HQ642928.1) and Salinispora sp. RL08-036SPS-B (KP250536.1) were used in this study. These Salinispora strains were cultured on $\mathrm{A} 1$ agar plates (10 $\mathrm{gL}^{-1}$ starch, $4 \mathrm{gL}^{-1}$ yeast extract, $2 \mathrm{gL}^{-1}$ peptone, $18 \mathrm{gL}^{-1}$ agar, $1 \mathrm{~L}$ artificial seawater). Starter cultures were inoculated from the colony grown on the A1 agar plate into $50 \mathrm{ml}$ medium $\mathrm{A} 1$ ( $10 \mathrm{gL}^{-1}$ starch, $4 \mathrm{gL}^{-1}$ yeast, $2 \mathrm{gL}^{-1}$ peptone, $1 \mathrm{~L}$ artificial seawater) in $250 \mathrm{ml}$ Erlenmeyer flasks containing a stainless steel spring and grown for 3 or 4 days at $28^{\circ} \mathrm{C}$ with shaking at 230 RPM (New Brunswick Innova 2300).

\section{Gene deletion of spt9}

i. Salinispora tropica CNB-440/ $\Delta$ spt9 was generated in the previous study. ${ }^{2}$

ii. Salinispora arenicola CNS-205/Aspt9.

DNA fragment A containing the upstream $3.0 \mathrm{~kb}$ region of spt9 was amplified by PCR with primer 1, 5'-cccccgggctgcaggaattcacctcgaacgcgcctactggcac-3' (annealing sequence boldfaced) and 2, 5'-caccatcgatggttatagccgggtgtcggtcatcggttg-3', and fragment B containing the downstream $3.0 \mathrm{~kb}$ region of spt9 was amplified by PCR with primer 3, 5'-accgacacccggctataaccatcgatggtgatctgtcgg-3' and 4, 5'ccagcctacacatcgaattcgcctgcgcaacgcatagtggagatc-3'.Fragment $A$ and $B$ were assembled with plJ773-derived fragment amplified by primer 5, 5'gaattcctgcagcccgggggatc-3' and 6, 5'- gaattcgatgtgtaggctggag-3' using Gibson assembly technique (kit was purchased from New England Biolabs), to yield plJ773$\Delta s p t 9$. The gene deletion vector plJ773- $\Delta$ spt9 was introduced into $S$. arenicola CNS-205 via intergeneric conjugation. The $\mathrm{Apr}^{R}$ exoconjugates from double-crossover were selected as previously reported procedure ${ }^{39}$. S. arenicola CNS-205/ $\Delta$ spt9 was isolated 
from $\mathrm{Apr}^{S}$ clones selected from the repeated subculture of $\mathrm{Apr}^{R}$ clones on the aparamycin-free agar plate. ${ }^{27}$

iii. Salinispora sp. RL08-036-SPS-B/Aspt9 and Salinispora sp. RL08-036-SPS-B/Aspt6

The gene inactivation experiments of spt9 and spt6 in Salinispora sp. RL08-036-SPS-B were performed using a PCR-targeting method. The coding region of spt9 was first replaced with an apramycin resistant gene aac(3)IV in cosmid 12E4-bla, which was isolated from the genomic library of Salinispora sp. RL08-036-SPS-B. The aac(3)IV disruption cassette was amplified from pHY773 by PCR primers with homology extensions targeting spt9 (primer pair, 5' atgaccgacacccggctactgaccccacctcacacgaccattccggggatccgtcgacc-3', and 5'ctgagcctctcgtcgagcaccccggtcaacacctggcgttgtaggctggagctgcttc-3'). The resulting vector 12E4-bla ( $\Delta s p t 9)$ was passaged through $E$. coli S17-1 and then introduced into Salinispora sp. RL08-036-SPS-B via intergeneric conjugation. The apramycin ${ }^{R}$ exconjugants were screened by PCR for the double cross-over mutants. Inactivation of spt6 was conducted similarly, except that an aac(3)IV-ermE* $\mathrm{p}$ disruption cassette (primer pair, 5'-cctgacccacgatccggacaagcagcgctatcacggcactcagttcccgccagcctgct-3', and 5'-gaaagcgataccgcgtggctgcccaccacgatgaaatcctaccaaccggcacgattgtg-3') was used to prevent the potential polar effects on downstream genes.

\section{LC-MS analysis of salinipostins and Sal-GBLs}

Each strain was cultured in a $250 \mathrm{~mL}$ Erlenmeyer flask containing $50 \mathrm{~mL}$ of medium $\mathrm{A} 1+\mathrm{BFe}$ (A1 plus $1 \mathrm{gL}^{-1} \mathrm{CaCO}_{3}, 40 \mathrm{mgL}^{-1} \mathrm{Fe}_{2}\left(\mathrm{SO}_{4}\right)_{3} \cdot 4 \mathrm{H}_{2} \mathrm{O}, 100 \mathrm{mgL}^{-1} \mathrm{KBr}$ ) at $28^{\circ} \mathrm{C}$ with shaking at 230 RPM (New Brunswick Innova 2300). Sterile Amberlite XAD-7HP resin (1 $\mathrm{g}$, Sigma-Aldrich) was added to each flask after $48 \mathrm{hr}$, and the fermentation was continued for an additional 4 days. The resins and cells were collected by filtration using cheese cloth or centrifugation, washed with distilled water, and soaked in acetone for 2 hr. The extract was concentrated in vacuo and the resultant residue dissolved in methanol. After filtration, an aliquot of the extract was subjected to LC-MS. For the salinipostin analysis, HR-LC-MS analysis was performed using a Phenomenex Kinetex XB- $\mathrm{C}_{18}$ column $(2.6 \mu \mathrm{m}, 100 \times 4.6 \mathrm{~mm}, 100 \AA)$ with the following conditions; positive mode, mobile phase $A$ : $0.1 \%$ formic acid in $\mathrm{H}_{2} \mathrm{O}$, mobile phase $\mathrm{B}$ : $0.1 \%$ formic acid in 
MeCN, $1.0 \mathrm{~mL} / \mathrm{min}, 0-8 \min (80-90 \% \mathrm{~B}), 8-13 \min (90 \%-100 \% \mathrm{~B}), 13-15 \min (100 \% \mathrm{~B})$. The ion at $m / z 445.2714$ (salinipostin $G$ and analogues), 459.2870 (salinipostin $B$ and analogues) and 473.3027 (salinipostin analogues) corresponding to the $[\mathrm{M}+\mathrm{H}]^{+}$ion was analyzed in the extracted ion chromatograms (EIC). Low-resolution LC-MS analysis was performed using a Phenomenex Kinetex XB-C ${ }_{18}$ column $(2.6 \mu \mathrm{m}, 100 \times 4.6 \mathrm{~mm}, 100 \AA)$ with the following conditions; positive mode, mobile phase $A$ : $0.1 \%$ formic acid in $\mathrm{H}_{2} \mathrm{O}$, mobile phase B: $0.1 \%$ formic acid in MeCN, $1.0 \mathrm{~mL} / \mathrm{min}, 0-8 \mathrm{~min}$ (80-90\% B), 8-10 min $(90 \%-100 \%$ B), $10-15$ min $(100 \%$ B), with a flow splitter. For the Sal-GBLs, LC-MS analysis was performed using a Phenomenex Luna $\mathrm{C}_{18}(2)$ column $(5.0 \mu \mathrm{m}, 150 \times 4.6$ $\mathrm{mm}, 100 \AA$ ) with the following conditions; positive mode, mobile phase A: $0.1 \%$ formic acid in $\mathrm{H}_{2} \mathrm{O}$, mobile phase $\mathrm{B}: 0.1 \%$ formic acid in $\mathrm{MeCN}, 0.7 \mathrm{~mL} / \mathrm{min}, 0-1 \mathrm{~min}(20 \% \mathrm{~B})$, $1-21 \mathrm{~min}(20 \%-100 \% \mathrm{~B})$, and $21-31 \mathrm{~min}(100 \% \mathrm{~B})$. lons at $\mathrm{m} / \mathrm{z} 215.1278$ and 201.1121 (Sal-GBL1 (2) and Sal-GBL2 (3), respectively) corresponding to the $[\mathrm{M}+\mathrm{H}]^{+}$ion were analyzed in the extracted ion chromatograms (EIC).

\section{Expression and purification of Spt9}

The spt9 sequence was amplified by PCR with gDNA of $S$. oceanensis CNT-854 as a template and primers: spt9-F, 5'- ctgtacttccaatccggatccatgaccgacacccggctact -3' (annealing sequence bold faced) and spt9-R, 5'cagtggtggtggtggtggtgctcgagtcaacacctggcgttgaccg -3' using PrimeSTAR HS (Takara). The $\mathrm{pET} 28 \mathrm{a}-\mathrm{MBP}$ was digested at BamH1 and $\mathrm{Xhol}$ sites. The amplified spt9 sequence and linear pET28a-MBP were assemble using Gibson assembly (New England Biolabs), and E. coli DH 10-beta (New England Biolabs) was transformed with Gibson assembly product. Complete nucleotide sequence of spt9 in the vector was confirmed by Sanger sequencing. The pET28a-MBP-spt9 was transformed to E. coli Rosetta2 (DE3). E. coli Rosetta2 cells harboring pET28a-MBP-spt9 were grown in Terrific Broth (TB) media containing $50 \mu \mathrm{g} / \mathrm{mL}$ kanamycin and $34 \mu \mathrm{g} / \mathrm{mL}$ chloramphenicol at $37^{\circ} \mathrm{C}$ until an OD600 of approximately 0.5 and then the temperature was lowered to $16^{\circ} \mathrm{C}$. After induction of the T7-promotor with $0.5 \mathrm{mM}$ of Isopropyl $\beta$-D-1-thiogalactopyranoside (IPTG), the cells were grown overnight at $16^{\circ} \mathrm{C}$. The cells were centrifuged and wash with buffer $(20 \mathrm{mM}$ Tris- $\mathrm{HCl}, 500 \mathrm{mM} \mathrm{NaCl}, 10 \%(\mathrm{v} / \mathrm{v})$ glycerol, $\mathrm{pH}$ 8.0), and then sonicated in the buffer containing $0.1 \mathrm{mM}$ phenylmethylsulfonyl fluoride (PMSF) on ice. The sonicated cells 
were centrifuged at $15000 \mathrm{~g}$ at $4^{\circ} \mathrm{C}$, and the supernatant was applied to a His-trap NiNTA column ( $5 \mathrm{~mL}$, GE Healthcare) according to the manufacture instruction using an Äktapurifier platform (GE Healthcare). The eluent containing $300 \mathrm{mM}$ imidazole buffer was desalted using PD-10 desalting column (GE Healthcare) with buffer (20 mM Tris$\mathrm{HCl}, 250 \mathrm{mM} \mathrm{NaCl}, 10 \%$ (v/v) glycerol, $\mathrm{pH}$ 8.0). The eluent fraction was concentrated by ultra-filtration using Centriprep centrifugal filter YM-10 (Merck Millipore). Protein concentration was determined by Bradford assay (Bio-Rad). For the cleavage of the MBP-tag, the Spt9-H-MBP was treated with Tobacco Etch Virus (TEV) protease at $4^{\circ} \mathrm{C}$ for $16 \mathrm{hr}$. The mixture was subjected a His-trap Ni-NTA column and the flow though was collected as the tag-free protein containing fraction. Tag-free Spt9 was desalted and concentrated as described above.

\section{Expression and purification of Spt6}

The spt6 sequence was amplified by PCR with gDNA of $S$. oceanensis CNT-854 as a template and primers: spt6-F, 5'-tgccgcgcggcagccatatgagcagtgtcgcggcctacgga-3' (annealing sequence bold faced) and spt6-R, 5'ctcgagtgcggccgcaagcttgctcatgacgctgccacggtg-3' using PrimeSTAR HS (Takara). The pET28a was digested at Ndel and HindIII sites. The amplified spt6 sequence and linear pET28a were assemble using Gibson assembly (New England Biolabs), and E. coli DH10-beta (New England Biolabs) was transformed with Gibson assembly product. Complete nucleotide sequence of spt6 in the vector was confirmed by Sanger sequencing. The pET28a-spt6 was transformed to E. coli Rosetta2 (DE3). E. coli Rosetta2 cells harboring pET28a-spt6 were grown in TB media containing $50 \mu \mathrm{g} / \mathrm{mL}$ kanamycin and $34 \mu \mathrm{g} / \mathrm{mL}$ chloramphenicol at $37^{\circ} \mathrm{C}$ until an OD600 of approximately 0.4 , and then the temperature was lowered to $18^{\circ} \mathrm{C}$. After induction of the T7-promotor with $1.0 \mathrm{mM}$ of Isopropyl $\beta$-D-1-thiogalactopyranoside (IPTG), the cells were grown overnight at $18^{\circ} \mathrm{C}$. The cells were centrifuged and wash with buffer $(20 \mathrm{mM}$ Tris- $\mathrm{HCl}, 500 \mathrm{mM} \mathrm{NaCl}$, $10 \%(\mathrm{v} / \mathrm{v})$ glycerol, $\mathrm{pH} 8.0)$, and then sonicated in the same buffer on ice. The sonicated cells were centrifuged at $15000 \mathrm{~g}$ at $4^{\circ} \mathrm{C}$, and the supernatant was applied to a His-trap Ni-NTA column ( $5 \mathrm{~mL}$, GE Healthcare) according to the manufacture instruction using an Äktapurifier platform (GE Healthcare). The eluent containing $300 \mathrm{mM}$ imidazole buffer was desalted using PD-10 desalting column (GE Healthcare) with buffer (20 mM Tris- 
$\mathrm{HCl}, 250 \mathrm{mM} \mathrm{NaCl}, 10 \%$ (v/v) glycerol, $\mathrm{pH}$ 8.0). The eluent fraction was concentrated by ultra-filtration using Centriprep centrifugal filter YM-10 (Merck Millipore). Protein concentration was determined by Bradford assay (Bio-Rad).

\section{Enzymatic reaction of Spt9}

The purified Spt9-H-MBP and tag-free Spt9 were used for the enzymatic reaction. The reaction mixture containing $100 \mu \mathrm{M}$ of Spt9-H-MBP, $1 \mathrm{mM} n$-butyl beta-ketoacyl $\mathrm{N}$ acetylcysteamine (4) and $1 \mathrm{mM}$ of dihydroxyacetone phosphate (DHAP, 5) was incubated in $50 \mathrm{mM}$ Mcllvaine buffer $\left(\mathrm{pH} \mathrm{7.0)}\right.$ at $30^{\circ} \mathrm{C}$ for $10 \mathrm{~min}$. 1 volume of $\mathrm{MeCN}$ was added to the reaction mixture and then centrifuged at $15000 \mathrm{~g}$ for $2 \mathrm{~min}$. The filtered supernatant was analyzed by LC-MS using a Phenomenex Luna $\mathrm{C}_{18}(2)$ column $(5.0 \mu \mathrm{m}$, $100 \times 4.6 \mathrm{~mm}, 100 \AA$ ) with the following conditions - negative mode, mobile phase $A$ : $0.1 \%$ formic acid in $\mathrm{H}_{2} \mathrm{O}$, mobile phase $\mathrm{B}: 0.1 \%$ formic acid in $\mathrm{MeCN}, 0.7 \mathrm{~mL} / \mathrm{min}, 0-3$ $\min (10 \% \mathrm{~B}), 3-14 \mathrm{~min}(10 \%-100 \% \mathrm{~B})$, and $14-18 \mathrm{~min}(100 \% \mathrm{~B})$. The ions at $\mathrm{m} / \mathrm{z}$ 277.0483 (compound 7) and 279.0639 (compound 8) corresponding to the [M-H] ion were analyzed in the extracted ion chromatograms (EIC). The collision energy in the MS/MS analysis of 7 was $10 \mathrm{eV}$.

\section{Reduction of butanolide using $\mathrm{NaBH}_{3} \mathrm{CN}$}

$50 \mu \mathrm{L}$ of freshly prepared $\mathrm{NaBH}_{3} \mathrm{CN}$ solution (10 mM in $\mathrm{EtOH}$ ) was added to the Spt9 enzymatic reaction mixture and incubated at room temperature for $30 \mathrm{~min}$. To this solution, four volumes of $25 \mathrm{mM}$ ammonium acetate buffer $(\mathrm{pH} 7.6)$ was added and then applied to the weak anion exchange resin, Macro-prep DEAE (Bio-Rad), packed in a glass pipette (column volume: $0.5 \mathrm{~mL}$ ). The column washed with buffer $(25 \mathrm{mM}$ ammonium acetate buffer, $20 \% \mathrm{MeOH}, \mathrm{pH} 7.6$ ), and eluted with $1 \% \mathrm{NH}_{4} \mathrm{OH}, 20 \% \mathrm{MeOH}$ aqueous solution. The eluent was filtered and subjected to the LC-MS analysis under the same condition as the Spt9-reaction analysis.

\section{Reduction of butenolide using S. tropica lysate}


Lysate was prepared from $25 \mathrm{~mL}$ of $S$. tropica CNB-440/Aspt9 culture. The mutant was cultured for 4-6 days in A1 media without resin. Cells were harvested from the culture by centrifugation $(5000 \mathrm{~g})$ and washed with buffer $(10 \mathrm{mM}$ Tris- $\mathrm{HCl}, 330 \mathrm{mM} \mathrm{NaCl}, 10 \%$ (v/v) glycerol, $0.5 \mathrm{mM}$ dithiothreitol (DTT), $\mathrm{pH} 7.5)$. Next, the cells were suspended in buffer and sonicated on ice. After removal of cell debris by centrifugation $\left(15000 \mathrm{~g}, 4^{\circ} \mathrm{C}\right.$, $10 \mathrm{~min}$ ), the supernatant was concentrated by ultra-filtration using a Centriprep centrifugal filter YM-10 (Merck Millipore). The resultant solution (protein $15 \mathrm{mg} / \mathrm{mL}$, determined by Bradford assay) was used for the butanolide reduction reaction. This lysate was added to the Spt9 reaction mixture with NADPH (final concentration $1 \mathrm{mM}$ ) and then incubated at $30^{\circ} \mathrm{C}$ for $1 \mathrm{hr}$. The reaction was stopped by addition of 1 volume of $\mathrm{MeCN}$ and then centrifuged at $15000 \mathrm{~g}$ for $2 \mathrm{~min}$. The supernatant was applied to the LC-MS analysis under the same condition as the Spt9-reaction analysis.

\section{Dephosphorylation of 8}

GBL phosphate (8) was incubated with 5 units of calf intestinal alkaline phosphatase (CIP, New England Biolabs) in $50 \mathrm{mM} \mathrm{HEPES} \mathrm{buffer}(\mathrm{pH} 8.0)$ at $30^{\circ} \mathrm{C}$ for $1 \mathrm{hr}$. 1 volume of $\mathrm{MeCN}$ was added to the reaction mixture and then centrifuged at $15000 \mathrm{~g}$ for $5 \mathrm{~min}$. The supernatant was applied to the LC-MS analysis after filtration using a spin filter. The lysate was prepared from a $25 \mathrm{~mL}$ culture of $S$. tropica CNB-440/Aspt9. LC-MS conditions were the same as Sal-GBLs analysis.

\section{Enzymatic reaction of Spt6}

A $50 \mu \mathrm{L}$ reaction contained $20 \mu \mathrm{M}$ Spt6, $1 \mathrm{mM}$ compound 8, $1 \mathrm{mM}$ ATP, $20 \mathrm{mM} \mathrm{MgCl}$, $50 \mathrm{mM}$ HEPES ( $\mathrm{pH} 8.0$ ). After incubation at $30^{\circ} \mathrm{C}$ for $60 \mathrm{~min}$, 1 volume of $\mathrm{MeCN}$ was added to the reaction mixture and centrifuged at $15000 \mathrm{~g}$ for $5 \mathrm{~min}$. The supernatant was analyzed by LC-MS/MS in two conditions: (1, Figure 4D, E) TSKgel Amide-80 HR (5 $\mu \mathrm{m}$, $4.6 \times 250 \mathrm{~mm}$, Tosoh), negative mode, mobile phase $\mathrm{A}: 10 \mathrm{mM}$ ammonium formate $\mathrm{H}_{2} \mathrm{O}$, mobile phase B: $10 \mathrm{mM}$ ammonium formate in $\mathrm{MeCN}: \mathrm{H}_{2} \mathrm{O}(9: 1, \mathrm{v} / \mathrm{v}), 0-3 \mathrm{~min}(90 \% \mathrm{~B}$, $0.7 \mathrm{~mL} / \mathrm{min}-0.5 \mathrm{~mL} / \mathrm{min}), 3-25 \mathrm{~min}(90 \%-50 \% \mathrm{~B}, 0.5 \mathrm{~mL} / \mathrm{min})$, and $25-30 \mathrm{~min}$ (50\% B, $0.5 \mathrm{~mL} / \mathrm{min})$.(2, Figure S17) Phenomenex Luna $\mathrm{C}_{18}(2)$ column $(5.0 \mu \mathrm{m}, 100 \times 4.6 \mathrm{~mm}$, $100 \AA$ ), negative mode, mobile phase A: $0.1 \%$ formic acid in $\mathrm{H}_{2} \mathrm{O}$, mobile phase $\mathrm{B}: 0.1 \%$ 
formic acid in MeCN, $0.7 \mathrm{~mL} / \mathrm{min}, 0-3 \mathrm{~min}(10 \% \mathrm{~B})$, 3-14 $\min (10 \%-100 \% \mathrm{~B})$, and $14-$ $18 \mathrm{~min}(100 \% \mathrm{~B})$. Ions at $\mathrm{m} / \mathrm{z} 279.0639$ (compound 8) and 359.0302 (compound 9) corresponding to the $[\mathrm{M}-\mathrm{H}]^{-}$ion were analyzed in the extracted ion chromatograms (EIC). The collision energy in the MS/MS analysis of 9 was $10 \mathrm{eV}$.

\section{Feeding experiments}

To a $50 \mathrm{~mL}$ preliminary cultured of $S$. tropica CNB-440/Aspt9, isolated Sal-GBL1 (2) and synthesized racemic Sal-GBL2 (3) in $\mathrm{MeOH}$, or synthesized racemic compound $\mathbf{8}$ in $\mathrm{MeOH}$ were independently added and cultured at $28^{\circ} \mathrm{C}$ for 1 day with shaking. Autoclaved Amberlite XAD-7HP was added to each culture and fermented for an additional 3 days. The cells and resins were harvested by centrifugation, washed with water, and then extracted with acetone for $2 \mathrm{hr}$. The extract was filtered and concentrated in vacuo using rotary evaporation. After suspension in $\mathrm{MeOH}$, the aliquot was applied to LC-MS for salinipostin analysis as described above.

\section{Extraction and purification of Sal-GBL1 (2)}

S. tropica CNB-440 was cultured in $2.8 \mathrm{~L}$ Erlenmeyer flasks containing $1 \mathrm{~L}$ of medium $\mathrm{A} 1+\mathrm{BFe}\left(\mathrm{A} 1\right.$ plus $1 \mathrm{gL}^{-1} \mathrm{CaCO}_{3}, 40 \mathrm{mgL}^{-1} \mathrm{Fe}_{2}\left(\mathrm{SO}_{4}\right)_{3} \cdot 4 \mathrm{H}_{2} \mathrm{O}, 100 \mathrm{mgL}^{-1} \mathrm{KBr}$ ) at $28^{\circ} \mathrm{C}$ with shaking at 230 RPM (New Brunswick Innova 2300). Sterile Amberlite XAD-7HP resin (20 $\mathrm{g}$, Sigma-Aldrich) was added to a flask after $48 \mathrm{hr}$ from inoculation, and the fermentation was continued for an additional 4 days. The resins and cells from $3 \mathrm{~L}$ culture were collected using cheese cloth, washed with water, and soaked in $1.5 \mathrm{~L}$ of acetone for $2 \mathrm{hr}$ with gentle shaking. The extract was filtered and concentrated in vacuo using rotary evaporation, and the concentrated crude extract was applied to a C18 column (Polygoprep C18, 25-40 $\mu \mathrm{m}, 100 \AA$ (Macherey-Nagel), 40 i.d. x $60 \mathrm{~mm}$ ). After the column washed with $\mathrm{MeOH}: \mathrm{H}_{2} \mathrm{O}(1: 4, \mathrm{v} / \mathrm{v})$, the compound was eluted with $\mathrm{MeOH}: \mathrm{H}_{2} \mathrm{O}(1: 1, \mathrm{v} / \mathrm{v})$ and $\mathrm{MeOH}: \mathrm{H}_{2} \mathrm{O}(4: 1, \mathrm{v} / \mathrm{v})$ stepwise. The resultant semi-pure extract was purified by HPLC using a Phenomenex Luna $\mathrm{C}_{18}(2)$ column $(5.0 \mu \mathrm{m}, 10$ i.d. $\times 250 \mathrm{~mm})$ with the following conditions - mobile phase $\mathrm{A}: 0.02 \%$ formic acid in $\mathrm{H}_{2} \mathrm{O}$, mobile phase $\mathrm{B}: 0.02 \%$ formic acid in MeCN, $2.0 \mathrm{~mL} / \mathrm{min}, 0-60 \mathrm{~min}$ (50\%-100\% B). Further purification was performed using a Phenomenex Kinetex $C_{18}$ column $(5.0 \mu \mathrm{m}, 10$ i.d. $\times 250 \mathrm{~mm})$ with the 
following conditions - mobile phase A: $0.02 \%$ formic acid in $\mathrm{H}_{2} \mathrm{O}$, mobile phase $\mathrm{B}: 0.02 \%$ formic acid in MeCN, $2.0 \mathrm{~mL} / \mathrm{min}, 0-10 \mathrm{~min}(30 \% \mathrm{~B}), 10-60 \mathrm{~min}(30 \%-100 \% \mathrm{~B})$. Column fractions were analyzed by MS to obtain purified Sal-GBL1 (2, 1.2 mg, clear solid).

\section{Structure elucidation of Sal-GBL1 (2)}

Structure elucidation of Sal-GBL1 (2) was accomplished through NMR and CD experiments. The purified compound was dissolved in $0.5 \mathrm{~mL}$ of $\mathrm{CDCl}_{3} .{ }^{1} \mathrm{H} \mathrm{NMR}$, a gradient COSY, a gradient HSQC, a gradient $\mathrm{HMBC}\left({ }^{3} \mathrm{~J}_{\mathrm{CH}}=8 \mathrm{~Hz}\right)$ were measured in a 5 $\mathrm{mm}$ NMR tube. The residual $\mathrm{CHCl}_{3}$ signal at $7.26 \mathrm{ppm}$ in the ${ }^{1} \mathrm{H}$ NMR spectrum and the ${ }^{13} \mathrm{CDCl}_{3}$ signal at $77.16 \mathrm{ppm}$ in the ${ }^{13} \mathrm{C}$ NMR spectra were used as internal references. All the proton and carbon signals were assigned based on the 2D NMR experiments (Figures. S20-23, Table S1). Keto-enol tautomerization gave small signal sets in ${ }^{1} \mathrm{H}$ NMR spectrum. The CD spectrum of 2 was measured in MeOH (Figure S24); $279 \mathrm{~nm}$ $(\Delta \varepsilon+0.465), 229 \mathrm{~nm}(\Delta \varepsilon+0.342)$. The observed Cotton effect was compared with that of synthetic 3-(R)-A-factor in the literature reported by Mori ${ }^{33,34 ;} 283.5 \mathrm{~nm}(\Delta \varepsilon+0.699)$, $221.0 \mathrm{~nm}(\Delta \varepsilon+0.420)$.

\section{Isolation of salinipostin B and G}

S. mooreana CNT-150 was cultured in $2.8 \mathrm{~L}$ Erlenmeyer flasks containing $1 \mathrm{~L}$ of medium $\mathrm{A} 1+\mathrm{BFe}\left(\mathrm{A} 1\right.$ plus $1 \mathrm{gL}^{-1} \mathrm{CaCO}_{3}, 40 \mathrm{mgL}^{-1} \mathrm{Fe}_{2}\left(\mathrm{SO}_{4}\right)_{3} \cdot 4 \mathrm{H}_{2} \mathrm{O}, 100 \mathrm{mgL}^{-1} \mathrm{KBr}$ ) at $28^{\circ} \mathrm{C}$ with shaking at 230 RPM (New Brunswick Innova 2300). The cells were harvested from $5 \mathrm{~L}$ culture by centrifugation at $15000 \mathrm{~g}$ for $15 \mathrm{~min}$ and soaked in $700 \mathrm{~mL}$ of $\mathrm{MeOH}$ overnight. After sonication, the crude extract was filtered and concentrated in vacuo using rotary evaporation. The concentrate was applied to a C18 column (Polygoprep C18, 25-40 $\mu \mathrm{m}$, $100 \AA$ (Macherey-Nagel), 40 i.d. x 60 mm) and eluted step-wise with $\mathrm{MeOH}: \mathrm{H}_{2} \mathrm{O}(2: 3$, $\mathrm{v} / \mathrm{v}), \mathrm{MeOH}: \mathrm{H}_{2} \mathrm{O}(4: 1, \mathrm{v} / \mathrm{v})$ and $\mathrm{MeOH}$. The salinipostin containing fractions were combined and purified by HPLC using a Phenomenex Luna $\mathrm{C}_{18}(2)$ column $(5.0 \mu \mathrm{m}, 10$ i.d. $\times 250 \mathrm{~mm}$ ) with the following conditions: mobile phase $\mathrm{A}: 0.02 \%$ formic acid in $\mathrm{H}_{2} \mathrm{O}$, mobile phase B: $0.02 \%$ formic acid in MeCN, $2.0 \mathrm{~mL} / \mathrm{min}, 0-60 \mathrm{~min}$ (80\%-100\% B). Salinipostins $B$ and $G$ were identified based on the MS/MS fragmentation pattern, UV profile and ${ }^{1} \mathrm{H}$ NMR and COSY spectra ${ }^{16}$. 


\section{Synthesis of beta-ketoheptanoyl-SNAC (4)}

As the mimic of beta-ketoacyl-ACP, beta-ketoheptanoyl $\mathrm{N}$-acetylcysteamine thioester (4, heptanethioic acid, 3-oxo-, S-[2-(acetylamino)ethyl] ester) was synthesized ${ }^{40,41}$. Methyl 3-oxoheptanoate (TCl America, $790 \mathrm{mg}, 5 \mathrm{mmol}$ ) was dissolved in $6 \mathrm{~mL}$ of aqueous 3.0 $\mathrm{M} \mathrm{NaOH}$ and $300 \mu \mathrm{L}$ of tetrahydrofuran, and then stirred at room temperature overnight. The residual alcohol was extracted with methylene chloride from the reaction mixture. The aqueous layer was diluted with $50 \mathrm{~mL}$ of water and acidified to approximately $\mathrm{pH} 3$ by adding $3 \mathrm{M}$ or $1 \mathrm{M} \mathrm{HCl}$. The acidified mixture was next extracted with $50 \mathrm{~mL}$ of methylene chloride. The organic phases were twice washed with saturated aqueous $\mathrm{NaCl}$. The methylene chloride was removed using rotary evaporator, and the resultant clear solid product (424 mg, 59\%) was applied to the next reaction without purification. Carboxylic acid (296 mg, $2.1 \mathrm{mmol}$ ) was dissolved in the anhydrous methylene chloride $(25 \mathrm{~mL}$ ) and stirred on ice for $15 \mathrm{~min}$. To this solution, $N$-acetylcysteamine (300 mg, 2.5 mmol), 4-(N,N-dimethylamino) pyridine (DMAP) (63 mg, $0.52 \mathrm{mmol}$ ) and $\mathrm{N}$-(3dimethylaminopropyl)- $N$-ethylcarbodiimide hydrochloride (EDCl) $(477 \mathrm{mg}, 2.5 \mathrm{mmol})$ were added. This solution was stirred at room temperature overnight. Saturated aqueous $\mathrm{NH}_{4} \mathrm{Cl}$ solution $(25 \mathrm{~mL}$ ) was added. and the organic phase was collected. The aqueous phase was extracted with ethyl acetate $(50 \mathrm{~mL})$ three times. The combined organic phase was concentrated under reduced pressure using rotary evaporation. The residue was purified by silica gel column chromatography with EtOAc to yield 4 (65.1 mg, 13\%, clear solid). HR-ESI-MS m/z 268.0977 [M+Na] (calcd for $\mathrm{C}_{11} \mathrm{H}_{19} \mathrm{NO}_{3} \mathrm{SNa}, 268.0978$ ). ${ }^{1} \mathrm{H}$ $\operatorname{NMR}\left(\mathrm{CDCl}_{3}, 600 \mathrm{MHz}\right) \delta 3.71(\mathrm{~s}, 2 \mathrm{H}), 3.48(\mathrm{t}, J=6.3 \mathrm{~Hz}, 2 \mathrm{H}), 3.11(\mathrm{t}, J=6.3 \mathrm{~Hz}, 2 \mathrm{H})$, 2.54 (t, $J=7.4 \mathrm{~Hz}, 2 \mathrm{H}), 2.00(\mathrm{~s}, 3 \mathrm{H}), 1.58(\mathrm{p}, J=7.5 \mathrm{~Hz}, 2 \mathrm{H}), 1.35(\mathrm{~m}, 2 \mathrm{H}), 0.92$ (t, $J=$ $7.4 \mathrm{~Hz}, 3 \mathrm{H}) ;{ }^{13} \mathrm{C} \mathrm{NMR}\left(\mathrm{CDCl}_{3}, 150 \mathrm{MHz}\right) \delta 205.6,192.6,170.9,57.3,43.3,39.4,29.3$, 25.6, 23.2, 22.2, 13.9. The signals derived from enol form of 4 were also observed (Figure S27).

\section{Synthesis and purification of dihydroxyacetone phosphate (5)}

Dihydroxyacetone phosphate was synthesized according to the literature ${ }^{35}$. Ethanol (83 $\mathrm{mL})$ treated with molecular sieves $3 \mathrm{~A}$, sulfuric acid $(0.5 \mathrm{~mL}, 9.3 \mathrm{mmol})$ and triethyl 
orthoformate $(17.5 \mathrm{~mL}, 105 \mathrm{mmol})$ were added to a dried round-bottom flask, and refluxed for $30 \mathrm{~min}$ under Argon gas. This solution cooled to $4^{\circ} \mathrm{C}$, then dihydroxy acetone dimer $(2.1 \mathrm{~g}, 11.7 \mathrm{mmol})$ was added. After $18 \mathrm{hr}$, dihydroxy acetone dimer $(2.1 \mathrm{~g}, 11.7$ $\mathrm{mmol}$ ) was added again and stirred for additional $24 \mathrm{hr}$. Sodium bicarbonate ( $3.2 \mathrm{~g})$ was added to this solution and stirred at $4^{\circ} \mathrm{C}$ for $30 \mathrm{~min}$, and then warmed to room temperature. Reaction mixture was filtered through a $2.5 \mathrm{~cm}$ of Celite and silica-gel (1:1), and washed with anhydrous ethyl acetate $(30 \mathrm{~mL})$. Combined filtrate was concentrated in vacuo and resuspended with ethyl acetate $(18 \mathrm{~mL})$ and then evaporated. Hexane (100 $\mathrm{mL}$ ) was added to the concentrate, and the formed white solid was collected by filtration. The white solid was washed with hexane and dried in vacuum to obtain pure 2,5diethoxy-p-dioxane-2,5-dimethanol (5.37 g, 87 \%). Resultant compound ( $2 \mathrm{~g}, 8.5 \mathrm{mmol}$ ) was dissolved in the pyridine $(9 \mathrm{~mL})$, placed on ice for $30 \mathrm{~min}$, and then diphenyl chlorophosphate $(3.5 \mathrm{~mL}, 17 \mathrm{mmol})$ was added dropwise over $50 \mathrm{~min}$. The reaction mixture was mixed with methyl tert-butyl ether $(30 \mathrm{~mL})$ and diethyl ether $(10 \mathrm{~mL})$, and washed with $\mathrm{H}_{2} \mathrm{O}$, cold $1 \mathrm{M} \mathrm{HCl}, \mathrm{H}_{2} \mathrm{O}$, saturated sodium bicarbonate and $\mathrm{H}_{2} \mathrm{O}$. The organic layer was evaporated in vacuo and dried in vacuum to afford 2,5-diethoxy- $p$ dioxane-2,5-dimethanol O-2,O-5-bis-(diphenyl phosphate) (yellow oil, $3.81 \mathrm{~g}, 70 \%$ ). This compound $(1.1 \mathrm{~g})$ was dissolved in ethanol $(75 \mathrm{~mL})$ and stirred with platinum oxide (50 $\mathrm{mg}$ ) under hydrogen gas for $24 \mathrm{hr}$. After filtration, the reaction mixture was evaporated and dried in vacuum. The resultant colorless oil was dissolved in $\mathrm{H}_{2} \mathrm{O}(5 \mathrm{~mL})$ and stirred at $65^{\circ} \mathrm{C}$ for $5 \mathrm{hr}$. The $\mathrm{pH}$ of this mixture was adjusted to $\mathrm{pH} 3.7$ by $3 \mathrm{M} \mathrm{NaOH}$ and $\mathrm{H}_{2} \mathrm{O}$. In order to improve the purity, a portion of the synthesized product was purified using a HILIC column, TSKgel Amide-80 HR (5 $\mu \mathrm{m}, 4.6 \times 250 \mathrm{~mm}$, Tosoh), with $\mathrm{CH}_{3} \mathrm{CN}: \mathrm{H}_{2} \mathrm{O}$ :formic acid (30:70:0.002, v/v/v) as the mobile phase at a flow rate of 0.7 $\mathrm{mL} / \mathrm{min}$. HR-ESI-MS m/z 168.9910 [M-H] $]^{-}$(calcd for $\mathrm{C}_{3} \mathrm{H}_{7} \mathrm{O}_{6} \mathrm{P}, 168.9907$ ). Keto-form of 5; ${ }^{1} \mathrm{H}$ NMR $\left(\mathrm{D}_{2} \mathrm{O}, 600 \mathrm{MHz}\right) \delta 4.54(\mathrm{~d}, J=7.8 \mathrm{~Hz}, 2 \mathrm{H}), 4.46(\mathrm{~s}, 2 \mathrm{H}) ;{ }^{13} \mathrm{C}$ NMR $\left(\mathrm{D}_{2} \mathrm{O}, 150\right.$ $\mathrm{MHz}) \delta$ 209.5, 66.6, 63.7. Diol-form 5; $\delta 3.79$ (d, $J=5.6 \mathrm{~Hz}, 2 \mathrm{H}), 3.53(\mathrm{~s}, 2 \mathrm{H}) ;{ }^{13} \mathrm{C}$ NMR $\left(\mathrm{D}_{2} \mathrm{O}, 150 \mathrm{MHz}\right) \delta 94.6,67.9,65.3$.

\section{Racemic synthesis of Sal-GBL2 (3) and Sal-GBL2-phosphate (8)}

Sal-GBL2 (3) was synthesized based on a literature procedure ${ }^{42}$ in which pentanoyl chloride was instead used to synthesize the desired pentanoyl-gamma-butyrolactone, 
Sal-GBL2 (3). HR-ESI-MS $m / z 201.1124[\mathrm{M}+\mathrm{H}]^{+}$(calcd for $\mathrm{C}_{10} \mathrm{H}_{17} \mathrm{O}_{4}, 201.1121$ ). ${ }^{1} \mathrm{H}$ NMR $\left(\mathrm{CDCl}_{3}, 600 \mathrm{MHz}\right) \delta 4.43(\mathrm{dd}, J=9.0,8.1 \mathrm{~Hz}, 1 \mathrm{H}), 4.14(\mathrm{dd}, J=9.0,6.8 \mathrm{~Hz}, 1 \mathrm{H}), 3.68$ (m, 2H), $3.23(\mathrm{~m}, 1 \mathrm{H}), 2.97$ (dt, $J=18.0,7.5 \mathrm{~Hz}, 1 \mathrm{H}), 2.63(\mathrm{dt}, J=18.0,7.3 \mathrm{~Hz}, 1 \mathrm{H}), 1.59$ $(\mathrm{p}, J=7.4 \mathrm{~Hz}, 2 \mathrm{H}), 1.33$ (q, $J=7.4 \mathrm{~Hz}, 2 \mathrm{H}), 0.90$ (t, $J=7.4 \mathrm{~Hz}, 3 \mathrm{H}) ;{ }^{13} \mathrm{C} \mathrm{NMR}\left(\mathrm{CDCl}_{3}\right.$, $150 \mathrm{MHz}) \delta 203.0,172.4,69.3,61.8,55.1,42.3,39.4,25.4,22.2,13.9$. The signals estimated to be derived from enol form of 3 were also observed in ${ }^{1} \mathrm{H}$ NMR spectrum (Figure S25). Phosphorylation of Sal-GBL2 (3) was accomplished using diphenyl phosphoryl chloride in pyridine and successive deprotection by Adams catalyst under hydrogen gas, yielding compound Sal-GBL2-phosphate (8, $4.8 \mathrm{mg})$. HR-ESI-MS m/z 279.0636 [M-H] $]^{-}$(calcd for $\left.\mathrm{C}_{10} \mathrm{H}_{16} \mathrm{O}_{7} \mathrm{P}, 279.0639\right) .{ }^{1} \mathrm{H}$ NMR $\left(\mathrm{CD}_{3} \mathrm{OD}, 600 \mathrm{MHz}\right) \delta 4.45$ (br t, $J=8.4 \mathrm{~Hz}, 1 \mathrm{H}$ ), 4.19 (br t, $J=7.5 \mathrm{~Hz}, 1 \mathrm{H}$ ), 4.01 (m, 2H), $3.29(1 \mathrm{H}), 2.93$ (dt, $J=18.0$, $7.4 \mathrm{~Hz}, 1 \mathrm{H}$ ), 2.68 (dt, $J=18.0,7.4 \mathrm{~Hz}, 1 \mathrm{H}), 1.58$ (p, $J=7.4 \mathrm{~Hz}, 2 \mathrm{H}), 1.35$ (q, $J=7.5 \mathrm{~Hz}$, 2H), 0.93 (t, $J=7.3 \mathrm{~Hz}, 3 \mathrm{H}) ;{ }^{13} \mathrm{C}$ NMR ( $\left.\mathrm{CD}_{3} \mathrm{OD}, 150 \mathrm{MHz}\right) \delta$ 203.3, 173.2, 70.1, 65.6, $43.0,39.4,26.0,22.8,13.9$. The signals estimated to be derived from enol form of 8 were also observed in ${ }^{1} \mathrm{H}$ NMR spectrum (Figure S31).

\section{Distribution and gene content of salinipostin-like biosynthetic gene clusters}

ClusterScout searches were performed to identify salinipostin-like biosynthetic gene clusters in other genomes ${ }^{43}$ using the following Pfam functions: spt1 Pfam00391, Pfam01326; spt2 Pfam00501; spt4 Pfam00550; spt5 Pfam07993; spt6 Pfam00334; spt7 Pfam01040; spt8 Pfam00296; spt9 Pfam03756. Independent searches were run with a minimum requirement of either 3,4 , or 5 Pfam matches, a maximum distance of $<10,000 \mathrm{bp}$ between each Pfam match, and a minimum distance of $1 \mathrm{bp}$ from the scaffold edge. The boundaries of each match were extended by a maximum of $10,000 \mathrm{bp}$ to help return full biosynthetic operons. For some searches, the spt9/afs $A$ Pfam was defined as essential. MultiGeneBlast ${ }^{44}$ was also used to query the contiguous salinipostin spt1-9 gene cluster from S. tropica CNB-440 against the NCBI GenBank Bacteria BCT subdivision database. Biosynthetic clusters retrieved from each ClusterScout and MultiGeneBlast search were inspected for each of the 9 spt Pfam hooks and biosynthetic gene clusters with similar organization to spt in S. tropica CNB-440 were saved for further analyses. 


\section{- ASSOCIATED CONTENT}

\section{Supporting Information}

NMR table of 2; HRMS spectra for 2 and 3; MS/MS spectra of 2, 7 and salinipostins; LCMS chromatograms of 3, 8, 9 and salinipostins; SDS-PAGE of Spt9 and Spt6; NMR spectra for 2-5, 8 (PDF)

\section{- AUTHOR INFORMATION}

\section{Corresponding Author}

Bradley S. Moore - Center for Marine Biotechnology and Biomedicine, Scripps Institution of Oceanography and Skaggs School of Pharmacy and Pharmaceutical Sciences, University of California San Diego, La Jolla, California 92093, United States; orcid.org/ 0000-0002-4652-1253; Phone: 858-822-6650; Email: bsmoore@ucsd.edu

\section{Authors}

Yuta Kudo - Center for Marine Biotechnology and Biomedicine, Scripps Institution of Oceanography, University of California San Diego, La Jolla, California 92093, United States; Frontier Research Institute for Interdisciplinary Sciences and Graduate School of Agricultural Science, Tohoku University, Sendai, Miyagi 980-8578, Japan; orcid.org/0000-0002-1586-2004

Takayoshi Awakawa - Center for Marine Biotechnology and Biomedicine, Scripps Institution of Oceanography, University of California San Diego, La Jolla, California 92093, United States; Graduate School of Pharmaceutical Sciences, The University of Tokyo, 7-3-1 Hongo, Bunkyo-ku, Tokyo 113-0033, Japan; orcid.org/0000-0003-25753175

Yi-Ling Du - Department of Chemistry, University of British Columbia, Vancouver, British Columbia V6T 1Z1, Canada; orcid.org/0000-0001-7072-4803

Peter A. Jordan - Center for Marine Biotechnology and Biomedicine, Scripps Institution of Oceanography, University of California San Diego, La Jolla, California 92093, United States 
Kaitlin E. Creamer - Center for Marine Biotechnology and Biomedicine, Scripps Institution of Oceanography, University of California San Diego, La Jolla, California 92093, United States; orcid.org/0000-0002-0666-2107

Paul R. Jensen - Center for Marine Biotechnology and Biomedicine, Scripps Institution of Oceanography, University of California San Diego, La Jolla, California 92093, United States; orcid.org/0000-0003-2349-1888

Roger G. Linington - Department of Chemistry, Simon Fraser University, Burnaby, British Columbia V5A 1S6, Canada; orcid.org/0000-0003-1818-4971

Katherine S. Ryan - Department of Chemistry, University of British Columbia, Vancouver, British Columbia V6T 1Z1, Canada; orcid.org/0000-0003-1643-1940

\section{Notes}

The authors declare no competing interests.

\section{- ACKNOWLEDGMENTS}

We thank to Dr. Brendan Duggan from UC San Diego for assistance with NMR measurements. We are grateful to Professor M. Reza Ghadiri and Dr. Luke J. Leman at the Scripps Research Institute for their help in the collection of CD measurements. We also thank to our colleagues Dr. Zachary D. Miles, Dr. Gregory C. A. Amos, Dr. Henrique R. Machado, Dr. Min Cheol Kim, Dr. Xiaoyu Tang, Dr. Hanna Luhavaya, Dr. Jie Li, Dr. Shaun McKinnie and Dr. Jonathan Chekan for experimental advice.

\section{-FUNDING SOURCES}

This work was supported by National Institutes of Health grant GM085770 (to B.S.M., and P.R.J.), the Japan Society for Promotion of Science (to Y.K., JSPS Overseas Research Fellowships), the Uehara Memorial Foundation (to T.A., Research Fellowship), and the National Science Foundation Graduate Research Fellowship Program under Grant No. DGE-1650112 (to K.E.C). 


\section{- REFERENCES}

(1) Nett, M.; Ikeda, H.; Moore, B. S. Genomic Basis for Natural Product Biosynthetic Diversity in the Actinomycetes. Nat. Prod. Rep. 2009, 26, 1362-1384.

(2) Amos, G. C. A.; Awakawa, T.; Tuttle, R. N.; Letzel, A.-C.; Kim, M. C.; Kudo, Y.; Fenical, W.; S. Moore, B.; Jensen, P. R. Comparative Transcriptomics as a Guide to Natural Product Discovery and Biosynthetic Gene Cluster Functionality. Proc. Natl. Acad. Sci. USA 2017, 114, E11121-E11130.

(3) Aroonsri, A.; Kitani, S.; Hashimoto, J.; Kosone, I.; Izumikawa, M.; Komatsu, M.; Fujita, N.; Takahashi, Y.; Shin-ya, K.; Ikeda, H.; Nihira, T. Pleiotropic Control of Secondary Metabolism and Morphological Development by KsbC, a Butyrolactone Autoregulator Receptor Homologue in Kitasatospora Setae. Appl. Environ. Microbiol. 2012, 78, 8015-8024.

(4) Li, X.; Wang, J.; Li, S.; Ji, J.; Wang, W.; Yang, K. ScbR-and ScbR2-Mediated Signal Transduction Networks Coordinate Complex Physiological Responses in Streptomyces Coelicolor. Sci. Rep. 2015, 5, 14831.

(5) Suroto, D. A.; Kitani, S.; Miyamoto, K. T.; Sakihama, Y.; Arai, M.; Ikeda, H.; Nihira, T. Activation of Cryptic Phthoxazolin A Production in Streptomyces Avermitilis by the Disruption of Autoregulator-Receptor Homologue AvaR3. J. Biosci. Bioeng. 2017, 124, 611-617.

(6) Takano, E. y-Butyrolactones: Streptomyces Signalling Molecules Regulating Antibiotic Production and Differentiation. Curr. Opin. Microbiol. 2006, 9, 287294.

(7) Hsiao, N. H.; Nakayama, S.; Merlo, M. E.; de Vries, M.; Bunet, R.; Kitani, S.; Nihira, T.; Takano, E. Analysis of Two Additional Signaling Molecules in Streptomyces Coelicolor and the Development of a Butyrolactone-Specific Reporter System. Chem. Biol. 2009, 16, 951-960.

(8) Ando, N.; Matsumori, N.; Sakuda, S.; Beppu, T.; Horinouchi, S. Involvement of Afs A in A-Factor Biosynthesis as a Key Enzyme. J. Antibiot. (Tokyo). 1997, 50, 847-852.

(9) Horinouchi, Sueharu, Beppu, T. Autoregulatory Factors and Communication in Actinomycetes. Annu. Rev. Microbilogylogy 1992, 46, 377-398. 
(10) Horinouchi, S. A Microbial Hormone, A-Factor, as a Master Switch for Morphological Differentiation and Secondary Metabolism in Streptomyces Griseus. Front. Biosci. 2002, 7, 2045-2057.

(11) Udwary, D. W.; Zeigler, L.; Asolkar, R. N.; Singan, V.; Lapidus, A.; Fenical, W.; Jensen, P. R.; Moore, B. S. Genome Sequencing Reveals Complex Secondary Metabolome in the Marine Actinomycete Salinispora Tropica. Proc. Natl. Acad. Sci. 2007, 104, 10376-10381.

(12) Duncan, K. R.; Crüsemann, M.; Lechner, A.; Sarkar, A.; Li, J.; Ziemert, N.; Wang, M.; Bandeira, N.; Moore, B. S.; Dorrestein, P. C.; Jensen, P. R. Molecular Networking and Pattern-Based Genome Mining Improves Discovery of Biosynthetic Gene Clusters and Their Products from Salinispora Species. Chem. Biol. 2015, 22, 460-471.

(13) Jensen, P. R.; Williams, P. G.; Oh, D. C.; Zeigler, L.; Fenical, W. SpeciesSpecific Secondary Metabolite Production in Marine Actinomycetes of the Genus Salinispora. Appl. Environ. Microbiol. 2007, 73, 1146-1152.

(14) Jensen, P. R.; Moore, B. S.; Fenical, W. The Marine Actinomycete Genus Salinispora: A Model Organism for Secondary Metabolite Discovery. Nat. Prod. Rep. 2015, 32, 738-751.

(15) Ziemert, N.; Lechner, A.; Wietz, M.; Millan-Aguinaga, N.; Chavarria, K. L.; Jensen, P. R. Diversity and Evolution of Secondary Metabolism in the Marine Actinomycete Genus Salinispora. Proc. Natl. Acad. Sci. USA 2014, 111, E1130E1139.

(16) Schulze, C. J.; Navarro, G.; Ebert, D.; Derisi, J.; Linington, R. G. SI_Salinipostins A-K, Long-Chain Bicyclic Phosphotriesters as a Potent and Selective Antimalarial Chemotype. J. Org. Chem. 2015, 80, 1312-1320.

(17) Yoo, E.; Schulze, C. J.; Stokes, B. H.; Onguka, O.; Yeo, T.; Mok, S.; Gnädig, N. F.; Zhou, Y.; Kurita, K.; Foe, I. T.; Terrell, S. M.; Boucher, M. J.; Cieplak, P.; Kumpornsin, K.; Lee, M. C. S.; Linington, R. G.; Long, J. Z.; Uhlemann, A. C.; Weerapana, E.; Fidock, D. A.; Bogyo, M. The Antimalarial Natural Product Salinipostin A Identifies Essential $\alpha / \beta$ Serine Hydrolases Involved in Lipid Metabolism in P. Falciparum Parasites. Cell Chem. Biol. 2020, 27, 143-157.e5.

(18) Vertesy, L.; Beck, B.; Bronstrup, M.; Ehrlich, K.; Kurz, M.; Muller, G.; Schummer, D.; Seibert, G. Cyclipostins, Novel Hormone-Sensitive Lipase Inhibitors from 
Streptomyces Sp. DSM 13381. II. Isolation, Structure Elucidation and Biological Properties. J. Antibiot. 2002, 55, 480-494.

(19) Kurokawa, T.; Suzuki, K.; Hayaoka, T.; Nakagawa, T. Cyclophostin, Acetylcholinesterase Inhibitor from Streptomyces Lavendulae. J. Antibiot. (Tokyo). 1993, 46, 1315-1318.

(20) Horinouchi, S.; Beppu, T. A - factor as a Microbial Hormone That Controls Cellular Differentiation and Secondary Metabolism in Streptomyces Griseus. Mol. Microbiol. 1994, 12, 859-864.

(21) Horinouchi, S. Mining and Polishing of the Treasure Trove in the Bacterial Genus Streptomyces. Biosci. Biotechnol. Biochem. 2007, 71, 283-299.

(22) Kato, J. -y.; Funa, N.; Watanabe, H.; Ohnishi, Y.; Horinouchi, S. Biosynthesis of Butyrolactone Autoregulators That Switch on Secondary Metabolism and Morphological Development in Streptomyces. Proc. Natl. Acad. Sci. USA 2007, 104, 2378-2383.

(23) Hsiao, N. H.; Söding, J.; Linke, D.; Lange, C.; Hertweck, C.; Wohlleben, W.; Takano, E. ScbA from Streptomyces Coelicolor A3(2) Has Homology to Fatty Acid Synthases and Is Able to Synthesize Y-Butyrolactones. Microbiology 2007, 153, 1394-1404.

(24) Corre, C.; Song, L.; O’Rourke, S.; Chater, K. F.; Challis, G. L. 2-Alkyl-4Hydroxymethylfuran-3-Carboxylic Acids, Antibiotic Production Inducers Discovered by Streptomyces Coelicolor Genome Mining. Proc. Natl. Acad. Sci. USA 2008, 105, 17510-17515.

(25) Arakawa, K.; Tsuda, N.; Taniguchi, A.; Kinashi, H. The Butenolide Signaling Molecules SRB1 and SRB2 Induce Lankacidin and Lankamycin Production in Streptomyces Rochei. ChemBioChem 2012, 13, 1447-1457.

(26) Arakawa, K. Manipulation of Metabolic Pathways Controlled by Signaling Molecules, Inducers of Antibiotic Production, for Genome Mining in Streptomyces Spp. Antonie van Leeuwenhoek, Int. J. Gen. Mol. Microbiol. 2018, $111,743-751$.

(27) Schlawis, C.; Kern, S.; Kudo, Y.; Grunenberg, J.; Moore, B. S.; Schulz, S. Structural Elucidation of Trace Components Combining GC/MS, GC/IR, DFT- 
Calculation and Synthesis-Salinilactones, Unprecedented Bicyclic Lactones from Salinispora Bacteria. Angew. Chem., Int. Ed. 2018, 57, 14921-14925.

(28) Schlawis, C.; Harig, T.; Ehlers, S.; Guillen-Matus, D. G.; Creamer, K. E.; Jensen, P.; Schulz, S. Extending the Salinilactone Family. ChemBioChem 2020.

(29) Letzel, A. C.; Li, J.; Amos, G. C. A.; Millán-Aguiñaga, N.; Ginigini, J.; Abdelmohsen, U. R.; Gaudêncio, S. P.; Ziemert, N.; Moore, B. S.; Jensen, P. R. Genomic Insights into Specialized Metabolism in the Marine Actinomycete Salinispora. Environ. Microbiol. 2017, 19, 3660-3673.

(30) Hara, O.; Beppu, T. Induction of Streptomycin-Inactivating Enzyme by A-Factor in Streptomyces Griseus. J. Antibiot. (Tokyo). 1982, 35, 1208-1215.

(31) Sato, K.; Nihira, T.; Sakuda, S.; Yanagimoto, M.; Yamada, Y. Isolation and Structure of a New Butyrolactone Autoregulator from Streptomyces Sp. FRI-5. J. Ferment. Bioeng. 1989, 68, 170-173.

(32) Takano, E.; Nihira, T.; Hara, Y.; Jones, J. J.; Gershater, C. J.; Yamada, Y.; Bibb, M. Purification and Structural Determination of SCB1, a Gamma-Butyrolactone That Elicits Antibiotic Production in Streptomyces Coelicolor A3(2). J. Biol. Chem. 2000, 275, 11010-11016.

(33) Mori, K. Synthesis and Absolute Configuration of A-Factor, the Inducer of Streptomycin Biosynthesis in Inactive Mutants of Streptomyces Griseus.

Tetrahedron Lett. 1981, 22, 3431-3432.

(34) Mori, K. Revision of the Absolute Configuration of A-Factor. Tetrahedron 1983, 39, 3107-3109.

(35) Jung, S. H.; Jeong, J. H.; Miller, P.; Wong, C. H. An Efficient Multigram-Scale Preparation of Dihydroxyacetone Phosphate. J. Org. Chem. 1994, 59, 71827184.

(36) Tang, W. J.; Gilman, A. G. Adenylyl Cyclases. Cell 1992, 70, 869-872.

(37) Wakimoto, T.; Egami, Y.; Nakashima, Y.; Wakimoto, Y.; Mori, T.; Awakawa, T.; Ito, T.; Kenmoku, H.; Asakawa, Y.; Piel, J.; Abe, I. Calyculin Biogenesis from a Pyrophosphate Protoxin Produced by a Sponge Symbiont. Nat. Chem. Biol. 2014, 10, 648-655. 
(38) Bose, U.; Ortori, C. A.; Sarmad, S.; Barrett, D. A.; Hewavitharana, A. K.; Hodson, M. P.; Fuerst, J. A.; Shaw, P. N. Production of N-Acyl Homoserine Lactones by the Sponge-Associated Marine Actinobacteria Salinispora Arenicola and Salinispora Pacifica. FEMS Microbiol. Lett. 2017, 364, 1-7.

(39) Schultz, A. W.; Oh, D. C.; Carney, J. R.; Williamson, R. T.; Udwary, D. W.; Jensen, P. R.; Gould, S. J.; Fenical, W.; Moore, B. S. Biosynthesis and Structures of Cyclomarins and Cyclomarazines, Prenylated Cyclic Peptides of Marine Actinobacterial Origin. J. Am. Chem. Soc. 2008, 130, 4507-4516.

(40) Bonnett, S. A.; Papireddy, K.; Higgins, S.; Del Cardayre, S.; Reynolds, K. A. Functional Characterization of an NADPH Dependent 2-Alkyl-3-Ketoalkanoic Acid Reductase Involved in Olefin Biosynthesis in Stenotrophomonas Maltophilia. Biochemistry 2011, 50, 9633-9640.

(41) Yu, G.; Nguyen, T. T. H.; Guo, Y.; Schauvinhold, I.; Auldridge, M. E.; Bhuiyan, N.; Ben-Israel, I.; lijima, Y.; Fridman, E.; Noel, J. P.; Pichersky, E. Enzymatic Functions of Wild Tomato Methylketone Synthases 1 and 2. Plant Physiol. 2010, 154, 67-77.

(42) Morin, J. B.; Adams, K. L.; Sello, J. K. Replication of Biosynthetic Reactions Enables Efficient Synthesis of A-Factor, a y-Butyrolactone Autoinducer from Streptomyces Griseus. Org. Biomol. Chem. 2012, 10, 1517-1520.

(43) Hadjithomas, M.; Chen, I. M. A.; Chu, K.; Huang, J.; Ratner, A.; Palaniappan, K.; Andersen, E.; Markowitz, V.; Kyrpides, N. C.; Ivanova, N. N. IMG-ABC: New Features for Bacterial Secondary Metabolism Analysis and Targeted Biosynthetic Gene Cluster Discovery in Thousands of Microbial Genomes. Nucleic Acids Res. 2017, 45, D560-D565.

(44) Medema, M. H.; Takano, E.; Breitling, R. Detecting Sequence Homology at the Gene Cluster Level with Multigeneblast. Mol. Biol. Evol. 2013, 30, 1218-1223. 